\title{
The Effect of the Affordable Care Act on the Labor Supply, Savings, and Social Security of Older Americans
}

Eric French, Hans-Martin von Gaudecker, and John Bailey Jones

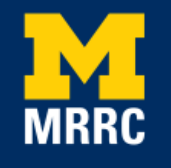

Project \#: UM15-11 


\title{
The Effect of the Affordable Care Act on the Labor Supply, Savings, and Social Security of Older Americans
}

\author{
Eric French \\ University College London
}

Hans-Martin von Gaudecker

Universität Bonn

John Bailey Jones

Federal Reserve Bank of Richmond and University at Albany, SUNY

October 2016

\author{
Michigan Retirement Research Center \\ University of Michigan \\ P.O. Box 1248 \\ Ann Arbor, MI 48104 \\ www.mrrc.isr.umich.edu \\ (734) 615-0422
}

\section{Acknowledgements}

The research reported herein was performed pursuant to a grant from the U.S. Social Security Administration (SSA) funded as part of the Retirement Research Consortium through the University of Michigan Retirement Research Center (5 RRC08098401-07). The opinions and conclusions expressed are solely those of the author(s) and do not represent the opinions or policy of SSA or any agency of the federal government. Neither the United States government nor any agency thereof, nor any of their employees, makes any warranty, express or implied, or assumes any legal liability or responsibility for the accuracy, completeness, or usefulness of the contents of this report. Reference herein to any specific commercial product, process or service by trade name, trademark, manufacturer, or otherwise does not necessarily constitute or imply endorsement, recommendation or favoring by the United States government or any agency thereof.

\section{Regents of the University of Michigan}

Michael J. Behm, Grand Blanc; Mark J. Bernstein, Ann Arbor; Laurence B. Deitch, Bloomfield Hills; Shauna Ryder Diggs, Grosse Pointe; Denise Ilitch, Bingham Farms; Andrea Fischer Newman, Ann Arbor; Andrew C. Richner, Grosse Pointe Park; Katherine E. White, Ann Arbor; Mark S. Schlissel, ex officio 


\title{
The Effect of the Affordable Care Act on the Labor Supply, Savings, and Social Security of Older Americans
}

\begin{abstract}
This paper assesses the effect of the Affordable Care Act (ACA) on the labor supply of Americans ages 50 and older. Using data from the Health and Retirement Study and the Medical Expenditure Panel Survey, we estimate a dynamic programming model of retirement that accounts for both saving and uncertain medical expenses. Importantly, we model the two key channels by which health insurance rates are predicted to change: the Medicaid expansion and the subsidized private exchanges.
\end{abstract}

\section{Citation}

French, Eric, Hans-Martin von Gaudecker, and John Bailey Jones. 2016. "The Effect of the Affordable Care Act on the Labor Supply, Savings, and Social Security of Older Americans.” Ann Arbor, MI. University of Michigan Retirement Research Center (MRRC) Working Paper, WP 2016-353. http://www.mrrc.isr.umich.edu/publications/papers/pdf/wp354.pdf

\section{Authors' Acknowledgements}

We thank the Michigan Retirement Research Center for financial support and Paul Van de Water for helpful comments. The views expressed in this paper are those of the authors and not necessarily those of the Social Security Administration, the MRRC, the Federal Reserve Bank of Richmond or the Federal Reserve System. 


\section{Introduction}

The Affordable Care Act (ACA) is the most significant reform to the health care sector in since the 1960s. The ACA's provisions fall into four main categories: (1) an expansion of Medicaid; (2) an overhaul of private non-group insurance, including community rating, coverage standards, the introduction of exchanges, subsidies, and purchase mandates; (3) a mandate for large employers to offer health insurance coverage, and subsidies for smaller employers; (4) miscellaneous provisions including reforms to coverage standards, the tax code, and the management of Medicare. ${ }^{1}$ In this paper, we assess the impact of the Medicaid and private non-group insurance provisions of the ACA on the labor supply and saving of Americans ages 50 and older. Using an estimated structural model of worker behavior, we focus on key provisions of the ACA that are likely to affect older workers.

We consider the following two sets of provisions. First, the ACA expands Medicaid eligibility for low-income households younger than 65. Prior to the ACA, low-income households nearing retirement qualified for Medicaid only if they were disabled. Moreover, under the ACA Medicaid applicants no longer face an asset test, meaning that they can qualify for Medicaid even if they hold significant wealth. The ability to carry wealth into retirement should make Medicaid more attractive for older workers. Overall, the Medicaid expansion could either increase or reduce labor supply by the elderly. Perhaps most likely, fewer people will work, as they can now qualify for Medicaid if they retire.

The second set of provisions involves non-group insurance. The ACA establishes exchanges where households without group coverage can purchase insurance. The policies offered on these exchanges must meet coverage standards, and they must be community-rated, i.e., insurers cannot price-discriminate by health. The ACA also requires uninsured households ineligible for Medicaid to purchase insurance, provides tax subsidies for most purchases, and levies penalties on those not complying. These changes should significantly alter the customer base and actuarial costs in the non-group market. Although the subsidies will allow most households to purchase non-group insurance more cheaply, healthy and/or lightly subsidized individuals may see their premiums rise. Because many workers lose their employer-provided insurance

\footnotetext{
${ }^{1}$ A comprehensive list can be found in The Henry J. Kaiser Family Foundation, (2013).
} 
after they leave their job (and the COBRA buy-in period expires), changes in the price of non-group insurance may change their retirement decisions. Because most people will be able to buy non-group health insurance more cheaply, early retirement will probably increase. Balancing against this, the subsidies provided under the ACA will allow uninsured low-income workers to purchase cheap insurance in the non-group market. Prior to the ACA these people may have used default on medical bills as a substitute for health insurance. However, default is a good substitute for insurance only when income and assets are low. Acquiring health insurance may encourage these workers to work and save more (Hsu, 2013).

Because the subsidies decrease with income, they also generate work disincentives. As Mulligan, (2013) points out, like most means-tested transfers, the ACA subsidies effectively impose a tax on income.

Our goal is to assess the quantitative importance of these effects. To do this, we will extend the structural labor supply and retirement model in French and Jones, (2011) to account for these reforms. We extend their model by adding in a much more detailed model of medical spending and insurance. We model explicitly how different types of health insurance plans affect the premiums and coinsurance rates that households face. We use data from the Health and Retirement Study (HRS) and the Medical Expenditure Panel Survey (MEPS) to estimate the structural model. We use the MEPS data to measure current medical expenditures, as well as who pays for these expenditures (out of pocket, private insurance, Medicaid, etc.). We use this information to estimate a dynamic programming model of labor supply and retirement behavior where individuals face realistic medical expense risk. Upon estimating the model, we conduct counterfactual experiments, where we modify the premia and co-insurance rates, net of subsidies and penalties, that households face.

\section{The Affordable Care Act}

The Affordable Care Act has many detailed provisions. Here we describe the key aspects of the law. 


\subsection{Medicaid}

Prior to the ACA, very few men younger than 65 were eligible for Medicaid, unless they were disabled. In 2014, participating states became able to offer Medicaid to all households earning less than $138 \%$ of the Federal Poverty Line, about $\$ 33,000$ for a family of four. Currently 32 states plus the District of Columbia have enacted the expansion.

To qualify for Medicaid, households must pass an income test. The income measure used in the test is Modified Adjusted Gross Income, which is Adjusted Gross Income from tax forms with a few minor modifications. Modified Adjusted Gross Income includes labor income, Social Security (but not SSI) income, as well as interest and other sources of capital income. An important change in the Medicaid eligibility rules is that there is no longer an asset test. As long as their asset income does not violate the income test, wealthy households can retire early and qualify for Medicaid.

\subsection{Health insurance exchanges, tax subsidies and penalties}

For uninsured households not eligible for Medicaid, the ACA facilitates the purchase of nongroup health insurance by establishing exchanges, providing subsidies, and imposing a purchase mandate. These changes should significantly alter participation, actuarial costs, and effective purchase prices in the non-group market.

The ACA establishes exchanges for the private purchase of individual non-group health insurance. Policies offered on these exchanges must belong to one of 4 categories - bronze, silver, gold and platinum - according to their actuarial value, the expected fraction of total medical expenses covered by the insurer. The benchmark category is the silver category, consisting of policies with actuarial values of at least $70 \%$, but actuarial values can range from $60 \%$ (bronze) to $90 \%$ (platinum). All plans must cap the total amount the individual pays out-of-pocket through deductibles and co-pays. In 2014 the out-of-pocket limit could not exceed $\$ 6,350$ for individual plans and $\$ 12,700$ for family plans. Above this level the insurer covers $100 \%$ of billable medical expenses. Another important aspect of the ACA is that all plans must be community-rated. Plans cannot differ by health status, although they may to some extent differ by age. 
Families with income between $100 \%$ and $400 \%$ of the Federal Poverty Limit (FPL) qualify for subsidies on their insurance premia. The subsidy formula specifies the fraction of income these households are expected to spend on a "typical" insurance policy. Premium expenditures on the typical plan in excess of this amount are rebated as tax credits. The expenditure cap rises with household income until income exceeds $400 \%$ of the FPL. Beyond that threshold there is no subsidy (Fernandez, 2014). In contrast, low income individuals are responsible for almost no costs, and can enjoy a subsidy as high as $100 \%$ of the premium. Households with income between $100 \%$ and $250 \%$ of the FPL are also entitled to "cost-sharing subsidies" that lower the out-of-pocket spending caps and raise the actuarial values of their policies. For families with income below $150 \%$ of the FPL, the out-of-pocket limit decreases to $36 \%$ of the normal limit, and the actuarial value of the plan increases to 94\%. (Fernandez 2014, Center on Budget and Policy Priorities 2015). Because both the premium and cost-sharing subsidies fall with income, they are implicit income taxes: see Mulligan, (2013) and Harris and Mok, (2015).

Households who do not purchase insurance or receive it through their employers must pay a "shared responsibility" penalty. This penalty, which is the larger of a income-independent

charge based on household composition or a fraction of household income, was phased in between 2014 and 2016. For example, the penalty for a family of 4 has risen from the greater of $\$ 285$ or $1 \%$ of income to the greater of $\$ 2,085$ or $2.5 \%$ of income.

\subsection{Employer Mandate}

The ACA affects the share of individuals who are offered employer provided health insurance, because of penalties that firms must pay. Firms employing fewer than 50 employees must provide health insurance, or pay a penalty of $\$ 3,000$ for each full time employee, up to a maximum of $\$ 2,000$ times the number of full- time employees minus 30 . The penalty is increased each year by the growth in insurance premiums.

If the employer has 25 or fewer employees and average wage up to $\$ 50,000$, it may be eligible for a health insurance tax credit.

Individuals working at large firms may see their coverage rise. Small low wage firms will have added incentives to cut their health insurance plans, since their workers can receive free or 
low cost health insurance from Medicaid or exchanges. Workers at these firms may be willing to accept the loss of health insurance for only a small increase in wages. For this reason, the Congressional Budget Office predicts that employer provided coverage will fall slightly under the ACA.

Because the predicted effect of the ACA comes mostly through the growth of non-group insurance on exchanges and through Medicaid, we focus on these margins. We assume no change in the structure of employer provided insurance: those covered by employer provided insurance before the reform continue to be covered, those not covered by employer provided coverage will continue not to be covered.

\subsection{Total Cost and Total Projected Increase in Insurance Coverage}

The Congressional Budget Office, (2015) projects the total net cost of the ACA's "insurance components" for 2016 to be $\$ 67$ billion, or roughly $0.4 \%$ of US GDP. Of this amount, $\$ 44$ billion is due to increased Medicaid costs, $\$ 41$ billion is due to the insurance exchange subsidies, andl $\$ 1$ billion is due to small business subsidies. The government is also projected to collect an additional $\$ 19$ billion through taxes and penalties.

In terms of insured individuals, the CBO projects the ACA to reduce the number of uninsured by 19 million in 2016. 20 million additional people would be covered through insurance exchanges, and 8 million additional people would be covered through through Medicaid and the Children's Health Insurance Program, while 10 million fewer people would receive employerprovided coverage or purchase off-exchange non-group coverage (Congressional Budget Office, 2015). According to the Gallup-Healthways poll (Marken, 2016), between the fourth quarter of 2013 and the third quarter of 2016, the uninsurance rate among people aged 18-64 fell by 7.5 percentage points. The fraction of people insured in the private non-group market rose by 3.9 percentage points and the fraction insured by Medicaid rose by 2.5 percentage points. Other types of insurance (e.g., Medicare) rose as well. The fraction of people insured by their employer fell by 0.8 percentage points. It is difficult to know how many of these workers, if any, lost their employer-provided health insurance as a result of the ACA. 


\section{The Model}

The model used in this paper expands the framework developed in French and Jones, (2011) to capture the detail of the U.S. health insurance system. The resulting model is very complex and has many parameters. Appendix A provides definitions for all the variables used in the main text.

\subsection{Preferences and Demographics}

Consider a household head with marital status $S P_{t}$, where $S P_{t}=1$ if the head has a spouse or partner and 0 otherwise. This individual seeks to maximize his expected discounted (where the subjective discount factor is $\beta$ ) lifetime utility at age $t, t=51,60, \ldots, 95$. Each period that he lives, the individual derives utility from consumption, $C_{t}$, and hours of leisure, $L_{t}$. The within-period utility function is of the form

$$
U\left(C_{t}, L_{t}\right)=\frac{1}{1-\nu}\left(\left(\frac{C_{t}}{\left(1+S P_{t}\right) \cdot 7}\right)^{\gamma} L_{t}^{1-\gamma}\right)^{1-\nu}
$$

We allow both $\beta$ and $\gamma$ to vary across individuals. Individuals with higher values of $\beta$ are more patient, while individuals with higher values of $\gamma$ place less weight on leisure. We follow Scholz and Seshadri, (2013) and many others by using equivalence scales, so that the consumption needs of a couple are less than twice as great as the consumption needs of two singles. The quantity of leisure is

$$
L_{t}=L-N_{t}-\phi_{P t} P_{t}-\phi_{R E} R E_{t}-\phi_{H} H_{t}
$$

where $L$ is the individual's total annual time endowment. Participation in the labor force is denoted by $P_{t}$, a 0-1 indicator equal to one when hours worked, $N_{t}$, are positive. The fixed cost of work, $\phi_{P t}$, is treated as a loss of leisure. Including fixed costs helps us capture the empirical regularity that annual hours of work are clustered around 2000 hours and 0 hours (Cogan, 1981). Following a number of studies, ${ }^{2}$ we allow preferences for leisure, in our case the value

\footnotetext{
${ }^{2}$ Examples include Rust and Phelan, (1997), Blau and Gilleskie, (2006) and Blau and Gilleskie, (2008), Gustman and Steinmeier, (2005), and van der Klaauw and Wolpin, (2008).
} 
of $\phi_{P t}$, to increase linearly with age. Workers that leave the labor force can re-enter; re-entry is denoted by the 0-1 indicator $R E_{t}=1\left\{P_{t}=1 \& P_{t-1}=0\right\}$, and individuals re-entering the labor market incur the cost $\phi_{R E}$. The quantity of leisure also depends on an individual's health status, $H_{t}$.

Following De Nardi, (2004), workers that die value bequests of assets, $A_{t}$, according to the function $b\left(A_{t}\right)$ :

$$
b\left(A_{t}\right)=\theta_{B} \frac{\left(A_{t}+\kappa\right)^{(1-\nu) \gamma}}{1-\nu}
$$

\subsection{Budget Constraints}

The individual holds three forms of wealth: assets (including housing); pensions; and Social Security. He has several sources of income: asset income, $r A_{t}$, where $r$ denotes the constant pre-tax interest rate; labor income, $W_{t} N_{t}$, where $W_{t}$ denotes wages; spousal income, ys $s_{t}$ pension benefits, $p b_{t}$; the sum of Social Security, Disability Insurance and Supplemental Security Income benefits, $s s_{t}$; and government transfers, $t r_{t}$. The asset accumulation equation is

$$
A_{t+1}=A_{t}+Y_{t}+t r_{t}-M_{t}-C_{t}
$$

$M_{t}$ denotes medical expenses. Post-tax income, $Y_{t}=Y\left(r A_{t}, W_{t} N_{t}, y s_{t}, s s_{t}, p b_{t}, \tau\right)$, is a function of taxable income and the tax structure $\tau . \tau$ includes general income taxes, payroll taxes, and taxation of Social Security benefits (Jones and Li, 2016).

Individuals face the borrowing constraint

$$
A_{t}+Y_{t}+t r_{t}-C_{t} \geq 0
$$

Because it is illegal to borrow against future Social Security benefits and difficult to borrow against many forms of future pension benefits, individuals with low non-pension, non-Social Security wealth may not be able to finance their retirement before their Social Security benefits become available at age 62 (Kahn 1988; Rust and Phelan 1997; Gustman and Steinmeier 
$2005) \cdot{ }^{3}$

Following Hubbard, Skinner, and Zeldes, (1994, 1995), government transfers provide a consumption floor:

$$
t r_{t}=\max \left\{0, C_{\min }-\left(A_{t}+Y_{t}\right)\right\}
$$

Equation (6) implies that government transfers bridge the gap between an individual's "liquid resources" (the quantity in the inner parentheses) and the consumption floor. Treating $C_{\min }$ as a sustenance level, we further require that $C_{t} \geq C_{\min }$. Our treatment of government transfers implies that individuals will always consume at least $C_{m i n}$, even if their out-ofpocket medical expenses exceed their financial resources. Equation (6) captures provisions such as the medically needy pathway for Medicaid, debt removal through bankruptcy, or debt forgiveness by hospitals.

\subsection{Health, Medical Expenses and Health Insurance}

The individual faces both health and mortality risk. His health status, $H_{t}$, can take on three values: good, bad, and disabled. The probability of surviving to age $t+1$, conditional on being alive at age $t$, is given by $s_{t}$. As described in appendix B.2, we allow $s_{t}$ and the transition probabilities for health to depend on previous health and age.

We define $Z_{t}$ as the sum of total medical expenses paid to providers, regardless of who pays for them. In our empirical analysis, the payment side of $Z_{t}$ will include payments by all payors, patients, insurers, Medicare, and Medicaid. The process for total expenses depends on health, marital status, age and the person-specific component $\psi_{t}$ :

$$
\ln Z_{t}=\mu_{z}\left(H_{t}, S P_{t}, t\right)+\sigma_{z}\left(H_{t}, S P_{t}, t\right) \times \psi_{t}
$$

\footnotetext{
${ }^{3}$ We assume time- $t$ medical expenses are realized after time- $t$ labor decisions have been made. We view this as preferable to the alternative assumption that the time- $t$ medical expense shocks are fully known when workers decide whether to hold on to their employer-provided health insurance. Given the borrowing constraint and timing of medical expenses, an individual with extremely high medical expenses this year could have negative net worth next year. Because many people in our data have unresolved medical expenses, medical expense debt seems reasonable.
} 
Even after controlling for health status, French and Jones, (2004) find that medical expenses are very volatile and persistent. Thus we model the person-specific component of medical expenses, $\psi_{t}$, as

$$
\begin{aligned}
\psi_{t} & =\zeta_{t}+\xi_{t}, \quad \xi_{t} \sim \mathcal{N}\left(0, \sigma_{\xi}^{2}\right) \\
\zeta_{t} & =\rho_{m} \zeta_{t-1}+\varepsilon_{t}, \quad \varepsilon_{t} \sim \mathcal{N}\left(0, \sigma_{\varepsilon}^{2}\right)
\end{aligned}
$$

where $\xi_{t}$ and $\epsilon_{t}$ are serially and mutually independent. $\xi_{t}$ is the transitory component, while $\zeta_{t}$ is the persistent component, with autocorrelation $\rho_{m}$.

There are several different types of health insurance model. As a first step, it is useful to characterize an individual by his access to employer-provided health insurance (EPHI), which we denote by $I_{t}$. At the beginning of a period, the individual finds himself in one of three mutually exclusive states:

1. retiree health insurance that he can hold on to until his death.

2. tied health insurance that he will lose shortly after his current job terminates. If a worker with tied health insurance leaves his job, he can keep his health insurance coverage for that year. This is meant to proxy for the fact that most firms must provide "COBRA" health insurance to workers after they leave their job. After one year of tied coverage and not working, the individual's insurance ceases. ${ }^{4}$

3. non-group insurance, i.e., an individual is on his own. He has the choice between purchasing insurance on the private non-group market or being uninsured.

Accounting for the choices of those in the non-group category, there are four types of privatelyprovided health insurance: retiree, tied, private, and uninsured.

Workers move between these insurance categories according to the rules defined in appendix A.1

\footnotetext{
${ }^{4}$ Although there is some variability across states as to how long individuals are eligible for employer-provided health insurance coverage, by Federal law most individuals are covered for 18 months (Gruber and Madrian, 1996). Given a model period of one year, we approximate the 18-month period as one year. We do not model the option to take up COBRA, assuming that the take-up rate is $100 \%$. The actual take-up rate is around $\frac{2}{3}$ (Gruber and Madrian, 1996). In French and Jones, (2011) we conducted a robustness test where we simulated the model assuming that the rate was $0 \%$, so that individuals transitioned from tied to non-group as soon as they stopped working, and found very similar labor supply patterns.
} 
(Table 10).

In addition to private coverage, individuals may receive Medicare and/or Medicaid benefits, according to the following rules:

1. Medicare insurance if he is either disabled or has reached the age of $65 .^{5}$

2. An individual will qualify for Medicaid insurance if he is poor enough to receive Supplemental Security Income and he is eithers disabled or has reached the age of $65 .{ }^{6}$

Both Medicare and Medicaid operate on top of the private coverage, although some combinations are impossible. We model the interaction of public and private health insurance as follows:

1. In actual practice the interaction of employer (retiree or tied) coverage with Medicare is complicated, depending on employment and firm size (Centers for Medicare and Medicaid Services, 2014). We assume instead that all individuals receiving both EPHI and Medicare share a "joint" plan that differs only by demographics $\left(t\right.$ and $\left.S P_{t}\right)$.

2. Many households purchase "Medigap" insurance to help pay for expenses not covered by Medicare. Our model abstracts away from this choice, and our empirical estimates will combine the two coverages.

3. Medicaid insurance is intended to be the payer of last resort, which is to say that Medicaid covers only the co-payments and deductibles left behind by other insurers.

4. While Medicaid covers Medicare premia, it does not cover the premia associated with private insurance. As Brown and Finkelstein, (2008) show, the latter provision can at times strongly discourage the purchase of private insurance.

5. The eligibility rules of the DI program require that the individual not work during the application period, although he may work later. As a result, an individual with tied

\footnotetext{
${ }^{5}$ Individuals who have paid into the Medicare system for at least 10 years become eligible at age 65 . A more detailed description of the Medicare eligibility rules is available at http://www.medicare.gov/.

${ }^{6}$ Our definition of Medicaid is that of "categorically needy" recipients, who qualify because their income and wealth are low, regardless of their medical conditions. The provision of Medicaid through other mechanisms, the most important of which is the "medically needy" provision, is captured by the consumption floor.
} 
coverage will lose this coverage if he transitions to DI and the associated Medicare and Medicaid coverage.

Let $I_{t}^{+}$denote the health insurance coverage the household receives after it has (possibly) decided whether to purchase private non-group coverage and after i's Medicaid eligibility has been determined. The realized value of $I_{t}^{+}$determines how the total health care cost $Z_{t}$ translates into out-of-pocket expenditures $M_{t}$ via the formula

$$
\begin{aligned}
M_{t} & =\operatorname{premium}\left(I_{t}^{+}, t, P_{t}, \widehat{Z}_{t}, S P_{t}\right)+\operatorname{copay}\left(I_{t}^{+}, Z_{t}\right), \\
\widehat{Z}_{t} & =\mathbb{E}\left[Z_{t} \mid t, H_{t}, \zeta_{t-1}\right] .
\end{aligned}
$$

Here $\operatorname{premium}(\cdot)$ is the health insurance premium, which can depend on expected medical

expenditures, $\widehat{Z}_{t}$; the function $\operatorname{copay}\left(I_{t}^{+}, Z_{t}\right)$ determines how much of $Z_{t}$ is assigned to the individual via co-payments and deductibles. We estimate both $\operatorname{premium}(\cdot)$ and $\operatorname{copay}(\cdot)$-function directly from the MEPS data. See the appendix for more details.

\subsection{Marital Status and Spousal Income}

Because spousal income can serve as insurance against medical shocks, and because marital status affects eligibility for Medicaid and other government programs, we include it in the model. We assume that when a spouse is present, spousal income $y s_{t}$ takes on two values: (i) zero; or (ii) a positive value that varies with age. We assume the transition probabilities for marital status, and whether the spouse has positive income depend on its current current marital status and income, current health, and age: see appendix B.5 for details.

\subsection{Wages}

We assume that the logarithm of wages at time $t, \ln W_{t}$, is a function of health status $\left(H_{t}\right)$, age $(t)$, hours worked $\left(N_{t}\right)$ and an autoregressive component, $\omega_{t}$ :

$$
\ln W_{t}=W\left(H_{t}, t\right)+\alpha \ln N_{t}+\omega_{t}
$$


The inclusion of hours, $N_{t}$, in the wage determination equation captures the empirical regularity that, all else equal, part-time workers earn relatively lower wages than full time workers. The autoregressive component $\omega_{t}$ has the correlation coefficient $\rho_{W}$ and the normallydistributed innovation $\eta_{t}$ :

$$
\omega_{t}=\rho_{W} \omega_{t-1}+\eta_{t}, \quad \eta_{t} \sim \mathcal{N}\left(0, \sigma_{\eta}^{2}\right)
$$

\subsection{Social Security, Disability Insurance, and Pensions}

Because pensions and Social Security generate potentially important retirement incentives, we model the two programs in detail.

Individuals receive no Social Security benefits until they apply. Individuals can first apply for benefits at age 62 . Upon applying the individual receives benefits until death. The individual's Social Security benefits depend on his Average Indexed Monthly Earnings ( $A I M E)$, which is roughly his average income during his 35 highest earnings years in the labor market.

The Social Security System provides three major retirement incentives. ${ }^{7}$ First, while income earned by workers with less than 35 years of earnings automatically increases their AIME, income earned by workers with more than 35 years of earnings increases their $A I M E$ only if it exceeds earnings in some previous year of work. Because Social Security benefits increase in $A I M E$, this causes work incentives to drop after 35 years in the labor market.

Second, the age at which the individual applies for Social Security affects the level of benefits. For every year before age 65 the individual applies for benefits, benefits are reduced by $6.67 \%$ of the age- 65 level. This is roughly actuarially fair. But for every year after age 65 that benefit application is delayed, benefits rise by $5.5 \%$ up until age 70 . This is less than actuarially fair, and encourages people to apply for benefits by age 65 .

Third, the Social Security Earnings Test taxes labor income of beneficiaries at a high rate. For individuals aged 62-64, each dollar of labor income above the "test" threshold (of $\$ 9,120$

\footnotetext{
${ }^{7}$ A description of the Social Security rules can be found in recent editions of the Green Book (Committee On Ways And Means, various years). Some of the rules, such as the benefit adjustment formula, depend on an individual's year of birth. Because we fit our model to a group of individuals that on average were born in 1933, we use the benefit formula for that birth year.
} 
in 1998) leads to a $1 / 2$ dollar decrease in Social Security benefits, until all benefits have been taxed away. For individuals aged 65-69 in 1998, each dollar of labor income above a threshold of $\$ 14,500$ leads to a $1 / 3$ dollar decrease in Social Security benefits, until all benefits have been taxed away. Although benefits taxed away by the earnings test are credited to future benefits, in 1998 the Social Security Earnings Test effectively taxes the labor income of beneficiaries aged 65-69. ${ }^{8}$ When combined with the aforementioned incentives to draw Social Security benefits by age 65, the Earnings Test discourages work after age 65. In 2000, the Social Security Earnings Test was abolished for those 65 and older. Because those born in 1933 (the average birth year in our sample) turned 67 in 2000, we assume that the earnings test was repealed at age 67 . These incentives are incorporated in the calculation of $s s_{t}$, which is defined to be net of the earnings test.

Associated with Social Security program is Disability Insurance (DI). Individuals with $H_{t}=$ disabled receive Disability benefits if their income is below a threshold. The level of the benefits is a function of $A I M E$. Individuals with low $A I M E$ and low assets also receive top-up benefits through the Supplemental Security Income (SSI) program. DI benefits are labor-income tested: individuals who earn more than $\$ 12,840$ in 2014 do not receive any benefits. We model this period-by-period conditional on $H_{t}=$ disabled.

Poor individuals who are elderly or disabled $\left(H_{t}=\right.$ disabled or $\left.t \geq 65\right)$ can qualify for Supplemental Security Income (SSI). Individuals with income below $Y^{S S I}$ and assets below $A^{S S I}$ receive a transfer of $\left(Y^{S S I}-Y_{t}\right)$. As described in Table 10, they also qualify for Medicaid.

Pension benefits, $p b_{t}$, are a function of the worker's age and pension wealth. Pension wealth (the present value of pension benefits) in turn depends on pension accruals. We assume that pension accruals are a function of a worker's age, labor income, and health insurance type, using a formula estimated from confidential HRS pension data. The data show that pension accrual rates differ greatly across health insurance categories; accounting for these differences is essential in isolating the effects of employer-provided health insurance. When finding an individual's decision rules, we assume further that the individual's existing pension wealth is a

\footnotetext{
${ }^{8}$ The credit rates are based on the benefit adjustment formula. If a year's worth of benefits are taxed away between ages 62 and 64, benefits in the future are increased by $6.67 \%$. If a year's worth of benefits are taxed away between ages 65 and 66, benefits in the future are increased by 5.5\%. See Olsen and Romig, 2013 for more details on the earnings test.
} 
function of his Social Security wealth, age, and health insurance type. Details of our pension model are described in Section 6.6; also see French and Jones, (2011).

\subsection{Recursive Formulation}

In addition to choosing hours, consumption, and potentially private non-group insurance vs. self-insurance, eligible individuals decide whether to apply for Social Security benefits; let the indicator variable $B_{t} \in\{0,1\}$ equal one if an individual has applied. In recursive form, the individual's problem can be written as

$$
\begin{aligned}
V_{t}\left(X_{t}\right)=\max _{C_{t}, N_{t}, B_{t}, I_{t}^{+}}\{ & \left.\frac{1}{1-\nu} C_{t}^{\gamma} L-N_{t}-\phi_{P t} P_{t}-\phi_{R E} R E_{t}-\phi_{H}\left(H_{t}\right)\right)^{1-\gamma}{ }^{1-\nu} \\
& +\beta\left(1-s_{t+1}\right) b\left(A_{t+1}\right) \\
& \left.\left.+\beta s_{t+1} \int V_{t+1} X_{t+1}\right) d F\left(X_{t+1} \mid X_{t}, t, C_{t}, N_{t}, B_{t}\right)\right\}
\end{aligned}
$$

subject to equations (5) and (6). The vector $X_{t}=\left(A_{t}, B_{t-1}, H_{t}, A I M E_{t}, I_{t}, P_{t-1}, \omega_{t}, \zeta_{t-1}, \Upsilon_{t}\right)$ contains the individual's state variables, while the function $F(\cdot \mid \cdot)$ gives the conditional distribution of these state variables, using equations (4) and (7)-(12). ${ }^{9}$ The solution to the individual's problem consists of the consumption rules, work rules, insurance choice rules, and benefit application rules that solve equation (13). These decision rules are found numerically using value function iteration.

\section{Modeling changes induced by the ACA}

\subsection{Medicaid expansion}

After 2014 low-income people can get Medicaid through the categorically needy channel, regardless of asset levels. In particular the eligibility test changes from

$$
I_{t}^{+}=\text {Medicaid if }\left\{Y_{t}<Y^{\text {cat-needy }}\left(S P_{t}\right) \text { and } A_{t}<A^{\text {cat-needy }}\left(S P_{t}\right)\right\}
$$

\footnotetext{
${ }^{9}$ Because we impute pension benefits as a function of the other state variables (as in French and Jones 2011), pension wealth is not a state variable.
} 


$$
I_{t}^{+}=\text {Medicaid if } \quad Y_{t}<Y^{\text {cat-needy }}\left(S P_{t}\right)
$$

In both cases the eligibility thresholds depend on marital status. As before the reform, individuals who fail the Medicaid eligibility tests but have catastrophic medical spending receive the minimum consumption level given by equation (6).

\subsection{Health insurance exchanges, tax subsidies and penalties}

The ACA will affect the premium $(\cdot)$ and $\operatorname{copay}(\cdot)$-functions for the non-group market. First, the $\operatorname{premium}(\cdot)$ function will no longer depend on expected medical expenses except those related to age, and $\operatorname{copay}(\cdot)$ function will have to satisfy the actuarial value and out-of-pocket limits specified by the law. Second, qualifying households will receive premium credits and costsharing subsidies. In addition, those who self-insure will have to pay the shared responsibility penalty for not buying insurance.

\section{Estimation}

To estimate the model, we adopt a two-step strategy, similar to the one used by Gourinchas and Parker, (2002) and French, (2005). In the first step we estimate or calibrate parameters that can be cleanly identified without explicitly using our model. For example, we estimate mortality rates and health transitions straight from demographic data. In the second step, we estimate the preference parameters of the model, as well as the consumption floor, using the method of simulated moments (MSM).

\subsection{Moment Conditions}

The objective of MSM estimation is to find the preference vector that yields simulated life-cycle decision profiles that "best match" (as measured by a GMM criterion function) the profiles from the data. The moment conditions that comprise our estimator are: 
1. Because an individual's ability to self-insure against medical expense shocks depends upon his asset level, we match $1 / 3 \mathrm{rd}$ and $2 / 3 \mathrm{rd}$ asset quantiles by age. We match these quantiles in each of $T$ periods (ages), for a total of $2 T$ moment conditions.

2. We match job exit rates by age for each health insurance category. With three health insurance categories (non-group, retiree and tied), this generates $3 T$ moment conditions.

3. Because the value a worker places on employer-provided health insurance may depend on his wealth, we match labor force participation conditional on the combination of asset quantile and health insurance status. With 2 quantiles (generating 3 quantile-conditional means) and 3 health insurance types, this generates $9 T$ moment conditions.

4. To help identify preference heterogeneity, we utilize a series of questions in the HRS that ask workers about their preferences for work. We combine the answers to these questions into a time-invariant index, pref $\in\{$ high,low, out $\}$, which is described in greater detail in Section 6.7. Matching participation conditional on each value of this index generates another $3 T$ moment conditions.

5. We match hours of work and participation conditional on our binary health indicator. This generates $4 T$ moment conditions.

6. Whether it is more attractive to buy private non-group health insurance or to self-insure against medical expense risk primarily depends on a household's asset level. Conditional on neither having access to employer-provided health insurance nor being eligible for Medicare or Medicaid, we match the fraction of households purchasing private insurance. Since everybody becomes eligible for Medicare at age 65 , this generates $3 T_{65}$ moment conditions, where $T_{65}$ denotes all ages included in the model before 65 .

Combined, the five preceding items result in $21 T+3 T_{65}$ moment conditions.

\subsection{Initial Conditions and Preference Heterogeneity}

A key part of our estimation strategy is to compare the behavior of individuals with different forms of employer-provided health insurance. If access to health insurance is an important 
factor in the retirement decision, we should find that individuals with tied coverage retire later than those with retiree coverage. In making such a comparison, however, we must account for the possibility that individuals with different health insurance options differ systematically along other dimensions as well. For example, individuals with retiree coverage tend to have higher wages and more generous pensions.

We control for this "initial conditions" problem in three ways. First, the initial distribution of simulated individuals is drawn directly from the data. Because households with retiree coverage are more likely to be wealthy in the data, households with retiree coverage are more likely to be wealthy in our initial distribution. Similarly, in our initial distribution households with high levels of education are more likely to have high values of the persistent wage shock $\omega_{t}$. Second, we model carefully the way in which pension and Social Security accrual varies across individuals and groups.

Finally, we control for unobservable differences across health insurance groups by introducing permanent preference heterogeneity, using the approach introduced by Heckman and Singer, (1984) and adapted by (among others) Keane and Wolpin, (1997) and van der Klaauw and Wolpin, (2008). Each ndividual is assumed to belong to one of a finite number of preference "types", with the probability of belonging to a particular type a logistic function of the individual's initial state vector: his age, wealth, initial wages, health status, health insurance type, medical expenditures, and preference index. ${ }^{10}$ We estimate the type probability parameters jointly with the preference parameters and the consumption floor.

In our framework, correlations between preferences and health insurance emerge because people with different preferences systematically select jobs with different types of health insurance coverage. Workers in our data set are first observed in their fifties; by this age, all else equal, jobs that provide generous post-retirement health insurance are more likely to be held by workers that wish to retire early. One way to measure this self-selection is to structurally model the choice of health insurance at younger ages, and use the predictions of that model to infer the correlation between preferences and health insurance in the first wave of the HRS.

\footnotetext{
${ }^{10}$ These discrete type-based differences are the only preference heterogeneity in our model. For this reason many individuals in the data make decisions different from what the model would predict. Our MSM procedure circumvents this problem by using moment conditions that average across many individuals.
} 
Because such an approach is computationally expensive, we instead model the correlation between preferences and health insurance in the initial conditions.

\subsection{Wage Selection}

We estimate a selection-adjusted wage profile using the procedure developed in French, (2005). First, we estimate a fixed effects wage profile from HRS data, using the wages observed for individuals who are working. The fixed-effects estimator is identified using wage growth for workers. If wage growth rates for workers and non-workers are the same, composition bias problems - the question of whether high wage individuals drop out of the labor market later than low wage individuals - are not a problem. However, if individuals leave the market because of a wage drop, such as from job loss, then wage growth rates for workers will be greater than wage growth for non-workers. This selection problem will bias estimated wage growth upward.

We control for selection bias by finding the wage profile that, when fed into our model, generates the same fixed effects profile as the HRS data. Because the simulated fixed effect profiles are computed using only the wages of those simulated agents that work, the profiles should be biased upwards for the same reasons they are in the data. We find this bias-adjusted wage profile using the iterative procedure described in French, (2005).

\section{Data and Calibrations}

\subsection{HRS Data}

We estimate the model using data from the Health and Retirement Survey (HRS) which is nationally representative sample of initially non-institutionalized individuals, and their spouses. We use data from everyone in the HRS who is at least age 51, which is the youngest age that core members of the sample are interviewed. With the exception of assets and medical expenses, which are measured at the household level, our data are for male household heads. The HRS surveys individuals every two years, so that we have 11 waves of data covering the period 1992-2012. The HRS also asks respondents retrospective questions about their work 
history that allow us to infer whether the individual worked in non-survey years.

As noted above, the Social Security rules depend on an individual's year of birth. To ensure that workers in our sample face a similar set of Social Security retirement rules, we fit our model to the data for the cohort of individuals born in the 1940s. However, when estimating the stochastic processes such as marital status, health and spousal income we use the full sample, including older individuals. With the exception of wages and spousal income, we do not adjust the data for cohort effects. Because our subsample of the HRS covers a fairly narrow age range, this omission should not generate much bias.

\subsection{Health and mortality}

We estimate health transitions and mortality rates simultaneously by fitting the transitions observed in the HRS to a multinomial logit model. We allow the transition probabilities to depend on age and current health status. We estimate annual transition rates: combining annual transition probabilities in consecutive years yields two-year transition rates we can fit to the HRS data. Appendix B.2 describes this process in detail.

We assign individuals to one of three health states: good, bad or disabled. First, we give individuals a health status of "good" if their self-reported health is excellent, very good or good, and a health status of "bad" if their self-reported health is fair or poor. We reclassify individuals as disabled if they are receiving Medicare and/or Medicaid benefits and are younger than 65 , regardless of self reported health. We use this measure of disability because we wish to capture both the cash transfers, and even more importantly, the Medicare or Medicaid insurance received by the disabled. Because DI recipients are transferred to Social Security at age 65 , and virtually everyone qualifies for Medicare at the same age, we are able to identify disability in our data only up to age 64 . From age 65 forward, we collapse the space of health outcomes to back to $\{\mathrm{bad}$, good $\}$. This requires us to estimate three health transition specifications: one for the three-state health measure; one for the two-state measure; and one for the transtion from three states to two between ages 64 and $65 .{ }^{11}$ To simplify the structural model, we assume that people in the "disabled" and "bad" health categories share the same

\footnotetext{
${ }^{11}$ Because we can assign people to good or bad health at any age, the data we use to estimate the two-state models encompass a broader age range than is used in the structural model.
} 
(total) medical expense distributions.

\begin{tabular}{|c|c|c|c|c|}
\hline \multicolumn{5}{|c|}{$\begin{array}{c}c \text { Ages } 50 \rightarrow \text { 51: } \text { Three states } \rightarrow \text { three states } \\
\text { Next Year }\end{array}$} \\
\hline \multirow{2}{*}{$\begin{array}{r}\text { Current Year } \\
\text { Disabled }\end{array}$} & Disabled & $\mathrm{Bad}$ & Good & Deceased \\
\hline & 95.4 & 0.9 & 0.5 & 3.1 \\
\hline Bad & 10.8 & 64.7 & 21.2 & 3.3 \\
\hline Good & 0.3 & 4.3 & 94.9 & 0.6 \\
\hline \multicolumn{5}{|c|}{$\begin{array}{c}\text { Ages } 60 \rightarrow \text { 61: } \text { Three states } \rightarrow \text { three states } \\
\text { Next Year }\end{array}$} \\
\hline \multirow{2}{*}{$\begin{array}{r}\text { Current Year } \\
\text { Disabled }\end{array}$} & Disabled & $\mathrm{Bad}$ & Good & Deceased \\
\hline & 92.8 & 1.4 & 0.7 & 5.0 \\
\hline Bad & 3.9 & 72.5 & 20.1 & 3.5 \\
\hline Good & 0.5 & 6.2 & 92.8 & 0.5 \\
\hline \multicolumn{5}{|c|}{$\begin{array}{c}\text { Ages } 64 \rightarrow \text { 65: Three states } \rightarrow \text { two states } \\
\text { Next Year }\end{array}$} \\
\hline \multirow{2}{*}{$\begin{array}{r}\text { Current Year } \\
\text { Disabled }\end{array}$} & $\mathrm{Bad}$ & Good & Deceased & \\
\hline & 62.8 & 31.0 & 6.2 & \\
\hline Bad & 78.7 & 17.5 & 3.8 & \\
\hline Good & 5.8 & 93.2 & 1.0 & \\
\hline \multicolumn{5}{|c|}{$\begin{array}{c}\text { Ages } \mathbf{7 0} \rightarrow \mathbf{7 1 :} \text { Two states } \rightarrow \text { two states } \\
\text { Next Year }\end{array}$} \\
\hline \multirow{2}{*}{$\begin{array}{r}\text { Current Year } \\
\text { Bad }\end{array}$} & Bad & Good & Deceased & \\
\hline & 77.1 & 15.3 & 7.6 & \\
\hline Good & 8.6 & 90.0 & 1.4 & \\
\hline \multicolumn{5}{|c|}{ Ages $80 \rightarrow \mathbf{8 1 :}$ Two states $\rightarrow$ two states } \\
\hline \multirow{2}{*}{$\begin{array}{r}\text { Current Year } \\
\text { Bad }\end{array}$} & Bad & Good & Deceased & \\
\hline & 73.4 & 12.9 & 13.6 & \\
\hline Good & 12.5 & 83.5 & 4.0 & \\
\hline
\end{tabular}

Table 1: Health Transition Probabilities

Table 1 shows transition probabilities for selected ages. As people age, good health becomes less persistent, and mortality rates rise. Disability is very persistent.

\subsection{The MEPS dataset}

An important limitation of the HRS data is that it only contains data on out-of-pocket medical spending and lacks information on other payors of medical care, such as Medicaid, Medicare and private health insurance. Although there there are some self-reported survey data on total 
billable medical expenditures in the HRS, these data are mostly imputed, and are considered to be of low quality. To circumvent this issue, we use data from the 1996-2012 waves of the Medical Expenditure Panel Survey (MEPS).

The MEPS is a nationally representative survey. Respondents are asked about health status, health insurance, and health care expenditures paid out-of-pocket, by Medicaid, by Medicare, private insurance and by other sources. The MEPS data are matched to information provided by providers. Although it does not capture certain types of medical expenditures, such as nursing home expenditures, it captures most of the sources of medical spending that are faced by individuals in their 50s and 60s. Sing, Banthin, Selden, Cowan, and Keehan, (2006) and Pashchenko and Porapakkarm, (forthcoming) provide extended comparisons between the MEPS data and the aggregate statistics.

MEPS respondents are interviewed up to 5 times over a 2 year period, forming short panels. We aggregate the data to an annual level. We use the same sample selection rules in the MEPS that we use for the HRS data. Specifically, we keep only men (although we also keep information on spouses of married men) ages 51 and older. drop those who were observed to be married over the sample period, work, or be younger than 72 in 1996, 74 in 1998, etc. As with the HRS data, we assign individuals a health status of "good" if self-reported health is excellent, very good or good, and are assigned a health status of "bad" if self-reported health is fair or poor.

\subsection{Total Medical Spending}

MEPS has data on total medical spending by all providers. We aggregate medical spending to the household level and model the mean of logged medical expenses modeled as a function of: a quartic in age, current health status, marital status, marital status interacted with age, health interacted with marital status, and health status interacted with age. We estimate these profiles using a fixed-effects estimator.

We use fixed-effects rather than OLS for two reasons. First, differential mortality causes the composition of our sample to vary with age, while we are interested in how medical expenses vary for the same individuals as they grow older. Second, cohort effects are likely 
to be important. Failure to account for the secular increase in medical expenses will lead to understate medical expenses growth by age. Cohort effects are captured in a fixed-effect estimator, as they are merely the average fixed effect for all members of a given cohort.

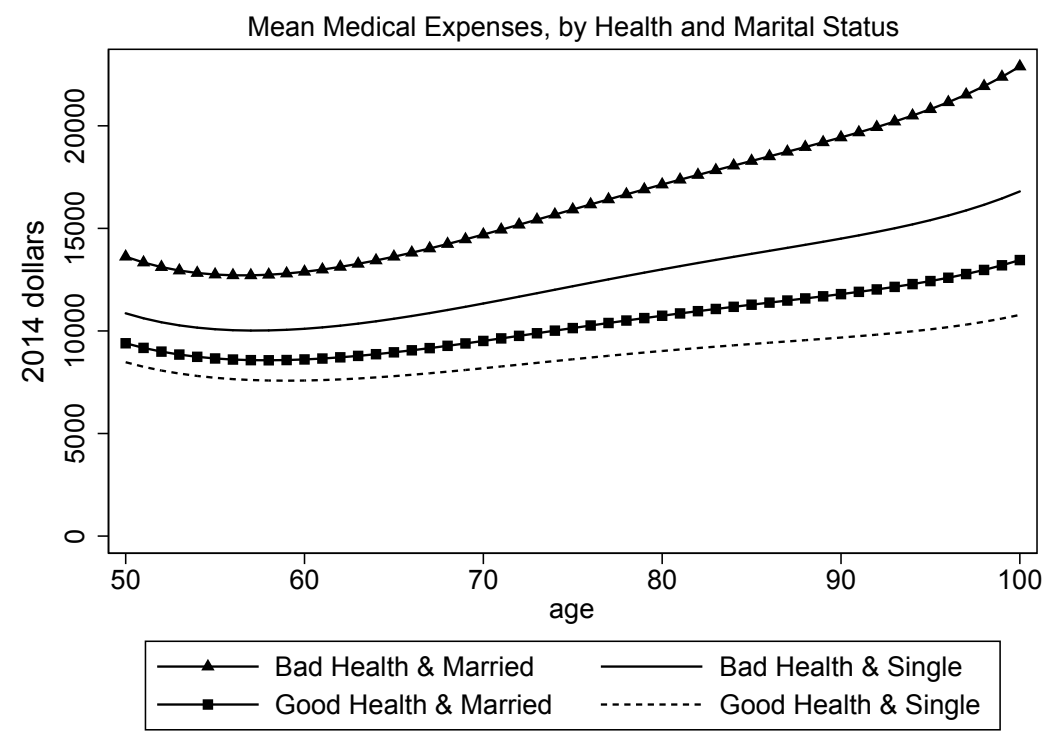

Figure 1: Total Medical Spending, By Age and Health Status

The combined variance of the medical expense shocks $\left(\zeta_{t}+\xi_{t}\right)$ is modeled with the same variables and functional form as the mean.

Figure 1 presents predicted medical spending, by age, health, and marital status. Average medical expenses for healthy people are about $50 \%$ lower than for unhealthy people, conditional on age. Medical spending is relatively constant until age 75 , when total medical spending begins to rise rapidly. De Nardi, French, Jones, and McCauley, (forthcoming) document similar patterns in the MCBS data.

The model-predicted distribution of medical spending lines up well with the data. For example, in the data mean household medical spending is $\$ 10,310$ and $\$ 13,570$ for those older and younger than 65 , respectively, of which $\$ 1,860$ and $\$ 2,180$ are spent out-of-pocket for those under and over 65, respectively. Table 2 presents further descriptives. It shows that the 95th percentile of total medical spending is $\$ 38,470$ and $\$ 48,860$ for those under and over 65 , respectively. 
Table 2 does not include insurance premia. We describe insurance premia in section 6.5 below.

\begin{tabular}{|c|c|c|c|c|}
\hline & \multicolumn{4}{|c|}{ Younger than 65} \\
\hline & \multicolumn{2}{|c|}{ Individual } & \multicolumn{2}{|c|}{ Household } \\
\hline & Total & Out-of-pocket & Total & Out-of-pocket \\
\hline Mean & 5,590 & 990 & 10,310 & 1,860 \\
\hline Median & 1,860 & 440 & 4,780 & 1,060 \\
\hline $90^{\text {th }}$ percentile & 12,670 & 2,420 & 24,030 & 4,370 \\
\hline \multirow[t]{4}{*}{$95^{\text {th }}$ percentile } & 22,450 & 3,670 & 38,470 & 6,130 \\
\hline & \multicolumn{4}{|c|}{65 and Older } \\
\hline & \multicolumn{2}{|c|}{ Individual } & \multicolumn{2}{|c|}{ Household } \\
\hline & Total & Out-of-pocket & Total & Out-of-pocket \\
\hline Mean & 8,640 & 1,370 & 13,750 & 2,180 \\
\hline Median & 3,690 & 720 & 6,900 & 1,310 \\
\hline $90^{t h}$ percentile & 21,250 & 3,190 & 32,770 & 5,000 \\
\hline $95^{\text {th }}$ percentile & 34,440 & 4,620 & 48,660 & 7,000 \\
\hline
\end{tabular}

Table 2: Distribution of Medical Spending, both Total and Out-of-Pocket, By Age, Individual versus Household

\subsection{Health Insurance and Medical Expenses}

We assign individuals to one of four mutually exclusive health insurance groups: retiree, tied, private and uninsured, as described in Section 3. In addition, they can have Medicaid or Medicare coverage if they are disabled. We allow for the fact that many people have Medicaid or Medicare coverage in addition to other coverage they might have. Both the HRS and MEPS have their own advantages for understanding the effect of health insurance. MEPS has better information on the copays and premia of different types of insurance. HRS has better information to understand the impact of health insurance on savings and labor supply. In both datasets individuals are asked similar questions, and we code the data similarly in both the HRS and MEPS.

Our interest is in understanding how insurance affects the male head of household within a family. However, many of these male heads are married. A head of household may be uninsured although his spouse may receive insurance from her own employer, for example. To address this issue we aggregate medical spending variables to the household level, so that we can focus on household medical expense risk, but use the head's insurance status. For this 
reason, many individuals who are "uninsured" may have positive insurance premia paid for their spouse's insurance.

Many people receive health insurance through multiple sources. In order to limit the number of possible health insurance states, we code individuals with multiple plans as having the types of plans that usually have smaller premia and contribute a larger share of the coverage. We consider individuals with both private non-group and employer coverage to have employer coverage. Those with both Medicare and Medicaid coverage are coded as having Medicaid coverage.

In the MEPS, individuals are asked about whether their insurance was obtained from an employer or from employer, or whether their insurance was privately purchased. However, we do not know whether an individual with employer-provided coverage could continue the coverage after they left their job. Thus we cannot distinguish between those who have retiree and tied coverage. Fortunately, French and Jones, (2011) show that those with tied coverage and retiree coverage have similar medical spending. Thus we assume that those with tied coverage have the same co-insurance rate those with retiree coverage.

The MEPS shows the medical costs covered by each payor. This allows us to better understand the share of spending paid out-of-pocket, versus paid by insurers. In MEPS, medical spending refers to spending over the last year. However, many people are insured for only part of the year. We classify individuals who are insured for part of year as insured. For those individuals, we may be understating the premia and the amount of insurance provided.

Table 3 presents descriptive evidence on household medical spending for those ages 50-64, by health insurance type. The table illuminates a few important facts. First, the uninsured tend to have lower total medical spending than other groups. ${ }^{12}$ The uninsured have average spending of $\$ 7,340$ per year, whereas it is $\$ 8,420$ for those who purchase insurance privately and $\$ 10,960$ for those with employer provided coverage. Second, for all groups, payments come from multiple sources. Many of those who are uninsured receive a large amount of payments from different payor sources. Of the $\$ 7,340$ in medical expenses of the uninsured, only $\$ 2,080$

\footnotetext{
${ }^{12}$ Some of these differences reflect differences in payment, since the MEPS medical expenditure data include only bills that were paid. One might be concerned that many medical bills of the uninsured go unpaid. However, MEPS also has data on claims made by providers. Claims made by providers, too, are lower for the uninsured.
} 


\begin{tabular}{lcccccc}
\hline \hline & & & & Private & Employer- \\
& Uninsured & Medicare & Medicaid & non-group & provided & Combined* \\
\hline Total expenses & 7,340 & 17,020 & 15,360 & 8,420 & 10,960 & 20,090 \\
Out-of-pocket & 2,080 & 2,920 & 1,040 & 2,620 & 1,910 & 2,340 \\
Pvt insurance & 580 & 850 & 320 & 2,730 & 4,260 & 8,570 \\
Medicare & 970 & 9310 & 4,050 & 840 & 490 & 4,340 \\
Medicaid & 80 & 100 & 6,740 & 20 & 30 & 620 \\
Other govt** & 1,110 & 1,310 & 470 & 100 & 160 & 350 \\
Other*** & 390 & 160 & 240 & 90 & 80 & 80 \\
Out-of-pocket insurance premia & & & & & \\
Private ins. & 450 & 520 & 110 & 5,940 & 2,800 & 2,220 \\
Medicare & 130 & 1,160 & 60 & 160 & 100 & 860 \\
\hline Employment rate & 0.65 & 0.08 & 0.20 & 0.69 & 0.84 & 0.27 \\
Labour income & 19,220 & 2,420 & 3,900 & 31,760 & 43,520 & 8,260 \\
Observations & 9,391 & 1,719 & 5,155 & 2371 & 33,326 & 1,142 \\
\hline \hline
\end{tabular}

MEPS data. Households with a man aged 50-64, all amounts in 2014 dollars

*Combined=Medicaid OR Medicare AND Private or Employer Provided.

*Other government plans=Tricare, Workers Comp, Other State/Local Plans.

$* * *$ Other $=$ unclassified sources including automobile, homeowner's, liability.

Table 3: Household medical spending, ages 50-64, By insurance type

is spent out-of-pocket, for example. Likewise, many or those with private insurance pay a large amount out-of-pocket. Those with private non-group and employer-provided insurance spend $\$ 2,620$ and $\$ 1,910$ are paid out-of-pocket by those who purchase insurance of the non-group market and group (ie. employer market). For this reason differences in coinsurance rates between the uninsured and insured are smaller than what one might initially guess.

Those with no insurance have their care paid for by multiple sources. After out-of-pocket spending, the largest payor of health care for the uninsured is "other government", which includes workers compensation and other state and local plans.

\section{Coinsurance rates and Insurance Premia: MEPS data}

For any given insurance type, the copay function copay $\left(I^{+}, Z_{t}\right)$ is characterized by three parameters: the deductible $\iota_{d}$; the coinsurance rate $\iota_{c}$; and the out-of-pocket maximum. $\iota_{o m}$. All costs up to the deductible $\iota_{d}$ are paid by the patient. The patient pays the fraction $\iota_{c}$ of any costs in excess of $\iota_{d}$, until his total payments reach the limit $\iota_{o m}$. Any costs in excess of 
$\iota_{\text {om }}$ are borne by the insurer. With this structure, we have

$$
\begin{aligned}
\operatorname{copay}\left(Z_{t} ; \iota_{d}, \iota_{c}, \iota_{o m}\right) & =\min \left\{\iota_{o m},\left[\min \left\{\iota_{d}, Z_{t}\right\}+\iota_{c} \cdot \max \left\{Z_{t}-\iota_{d}, 0\right\}\right]\right\} \\
& =\min \left\{\iota_{o m},\left[\iota_{c} Z_{t}+\left(1-\iota_{c}\right) \min \left\{\iota_{d}, Z_{t}\right\}\right]\right\} .
\end{aligned}
$$

We estimate separate copay functions for each insurance type, using non-linear least squares. While the estimation procedure is straightforward, the treatment of the data is not: Appendix A.1 provides additional details. Table 4 shows the estimated parameters. Of note is that the copay rate for the uninsured is 0.675 , rather than 1 . This reflects payments covered by other government insurance.

\begin{tabular}{lccc}
\hline & $\begin{array}{c}\text { Coductible } \\
\left(\iota_{d}\right)\end{array}$ & $\begin{array}{c}\text { Rate } \\
\left(\iota_{c}\right)\end{array}$ & $\begin{array}{c}\text { Out-of-pocket } \\
\text { Limit } \\
\left(\iota_{\text {om }}\right)\end{array}$ \\
Uninsured & 1,340 & 0.6753 & $\mathrm{NA}$ \\
Medicaid & 0 & 0.0360 & $\mathrm{NA}$ \\
Medicare & 2,270 & 0.1271 & $\mathrm{NA}$ \\
Employer provided-Medicare & 580 & 0.1911 & 4,810 \\
Employer provided & 710 & 0.1891 & 6,260 \\
Private Non-Group & 2,250 & 0.2094 & 14,440 \\
\hline
\end{tabular}

Notes: Employer provided includes both Retiree and Tied coverage.

NA means no out-of-pocket limit

Table 4: Copayment Parameters

Next we estimate the insurance premia paid by households. Premia depend on marital status and in the non-group market also depend on predicted medical expenses. To do this we regress the total insurance premia paid by by all members of the household on the male head's insurance type, and predicted medical spending, both before and after age 65 . We predict the household's medical spending using the previous year's medical spending. Table 5 shows predicted premia for different groups of people.

It also shows how predicted total medical spending (as predicted by last year's total medical spending, age, and health status) affects current insurance premia. We find that for every $\$ 1$ increase in predicted total medical spending, insurance premia rises by $\$ 0.11$, showing that although higher predicted medical spending increases insurance premia, it is much less than dollar for dollar. Part of this is likely due to the fact that many states mandated partial 


\begin{tabular}{|c|c|c|c|c|c|c|c|c|}
\hline & EPHI & $\begin{array}{l}\text { EPHI - } \\
\text { Medicare }\end{array}$ & $\begin{array}{l}\text { EPHI- } \\
\text { Medicaid }\end{array}$ & $\begin{array}{c}\text { EPHI- } \\
\text { Medicare- } \\
\text { Medicaid }\end{array}$ & Private & Medicare & Medicaid & $\begin{array}{l}\text { Medicare- } \\
\text { Medicaid }\end{array}$ \\
\hline \multicolumn{9}{|c|}{ Under 65} \\
\hline Constant & 1,237 & 2,132 & 820 & 986 & 2,907 & 1,299 & 182 & 162 \\
\hline Married & 1,210 & 826 & 1,109 & 260 & 2,069 & 503 & 63 & 60 \\
\hline \multicolumn{5}{|c|}{ Predicted medical spending } & 0.11 & & & \\
\hline \multicolumn{9}{|c|}{ Over 65} \\
\hline Constant & & 2,027 & & 640 & & 1,447 & & 59 \\
\hline Married & & 1,478 & & 812 & & 1,415 & & 314 \\
\hline
\end{tabular}

Table 5: Insurance Premia

or complete community rating. Furthermore, Buchmueller and DiNardo, (2002) and Herring and Pauly, (2006) show that even in states that did not mandate community rating, higher expected medical spending only leads to modestly higher insurance premia. Furthermore, Herring and Pauly, (2006) show that this is not due to selection issues coming from people being denied coverage when facing high medical expenses. Perhaps unsurprisingly, we found that predicted medical expenses has little impact on insurance premia for those with employer or government provided insurance. For this reason, and for parsimony, we set these coefficients to zero.

To better understand the parameters in Tables 4 and 5, Figure 2 uses the parameters to show predicted out-of-pocket medical spending for married households with different different levels of medical spending, summing over both insurance premia and copays. Of special interest is the difference between the budget line for the uninsured versus the budget line for those with private non-group insurance. The budget line shows that for households with less than $\$ 17,000$ in total medical spending, choosing to be uninsured is cheaper than choosing to be insured in the private non-group market. However, many households with lower total medical spending will select private insurance, since total medical spending is uncertain at the time of selection of insurance. Many of those whose expect medical spending above $\$ 17,000$ ex ante will wind up with medical spending below this level ex post. Furthermore, risk aversion implies that those with expected medical spending below $\$ 17,000$ may still purchase insurance to insure themselves against the risk of higher medical spending. Likewise, many households with total 
medical spending over $\$ 17,000$ will select to be uninsured, for two reasons. First, they may have expected medical spending that is lower than realized. Second, if they have low assets and income, their copays will be covered by the consumption floor. Thus they will use the implicit insurance from the consumption floor as a substitute for private insurance.

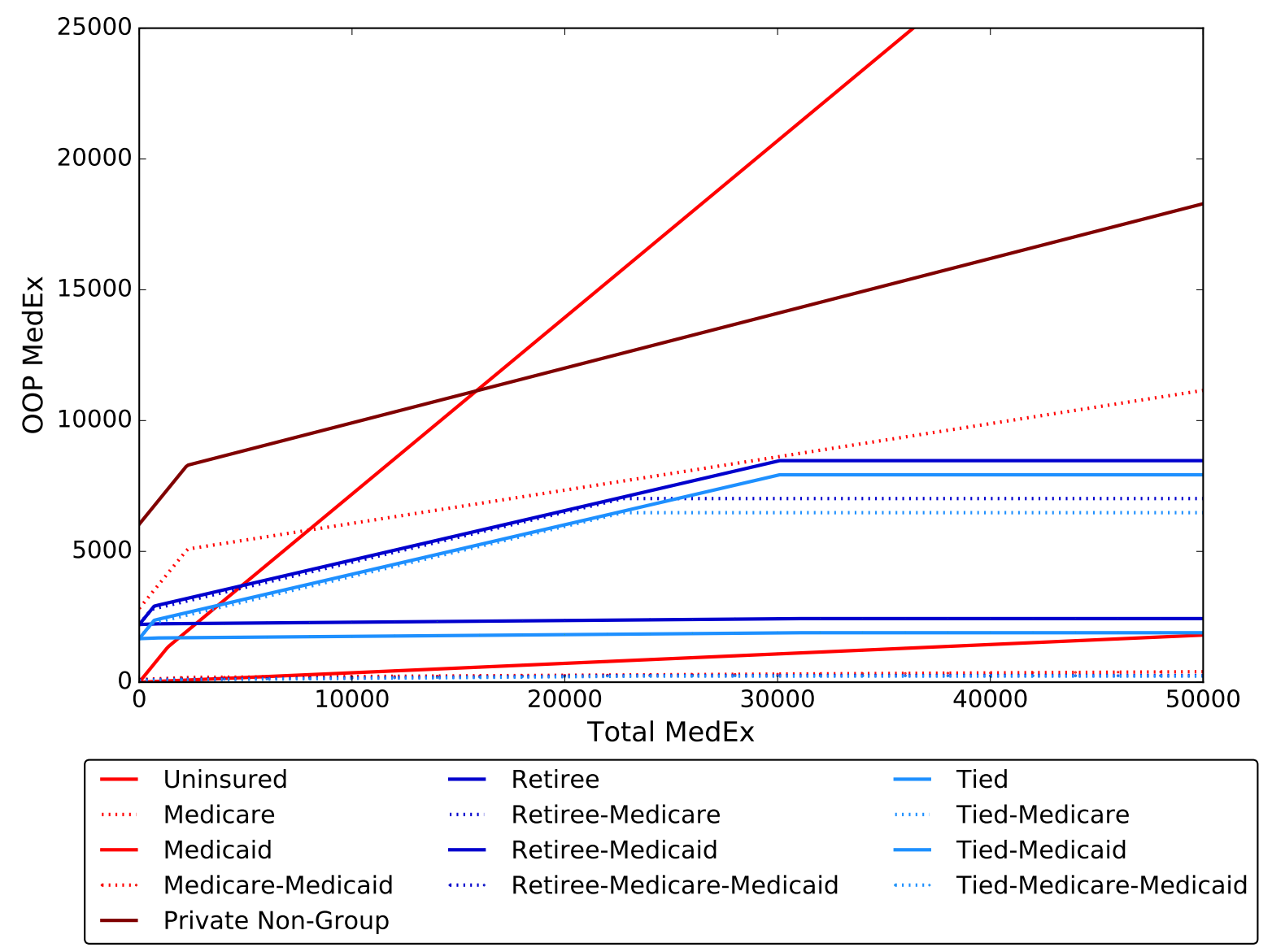

Figure 2: Budget sets By health insurance type, total expenses up to $\$ 50,000$

\section{Idiosyncratic Shocks}

The parameters for the idiosyncratic process $\psi_{t},\left(\sigma_{\xi}^{2}, \sigma_{\epsilon}^{2}, \rho_{m}\right)$, are taken from French and Jones, (2004, "fitted" specification). Table 6 presents the parameters, which have been normalized so that the overall variance, $\sigma_{\psi}^{2}$, is one. Table 6 reveals that at any point in time, the transitory component generates almost $67 \%$ of the cross-sectional variance in medical expenses. The results in French and Jones reveal, however, that most of the variance in cumulative lifetime 


\begin{tabular}{llc}
\hline Parameter & Variable & $\begin{array}{c}\text { Estimate } \\
\text { (Standard Errors) }\end{array}$ \\
\hline$\rho_{m}$ & autocorrelation of persistent component & $0.925(0.003)$ \\
$\sigma_{\epsilon}^{2}$ & innovation variance of persistent component & $0.04811(0.008)$ \\
$\sigma_{\xi}^{2}$ & innovation variance of transitory component & $0.6668(0.014)$ \\
\hline
\end{tabular}

Table 6: Variance and Persistence of Innovations to Medical Expenses

medical expenses is generated by innovations to the persistent component. For this reason, estimates of the cross sectional distribution of medical expenses understate the lifetime risk of medical expenses. Given the autocorrelation coefficient $\rho_{m}$ of 0.925 , this is not surprising.

\subsection{Pension Accrual}

Our formula for pension accrual rates comes from French and Jones, (2011), who estimate them using confidential HRS pension data. Figure 3, taken from French and Jones, (2011), shows the average pension accrual rates generated by this formula when we simulate the model.

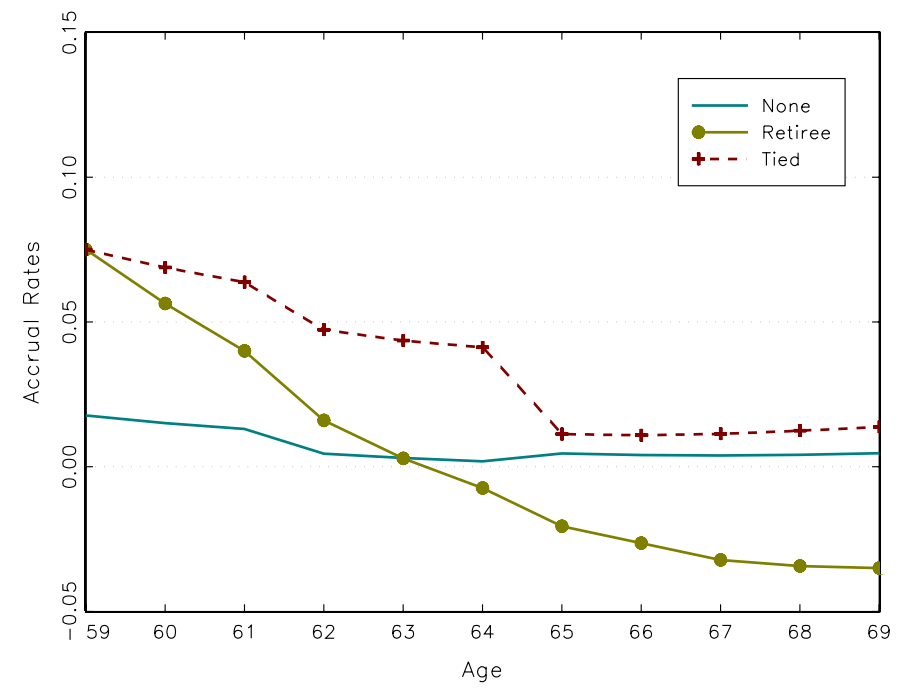

Figure 3: Average Pension Accrual Rates, By Age and Health Insurance CoverAGE

Figure 3 reveals that workers with retiree coverage face the sharpest drops in pension accrual after age $60 .{ }^{13}$ While retiree coverage in and of itself provides an incentive for early retirement,

\footnotetext{
${ }^{13}$ Because Figure 3 is based on our estimation sample, it does not show accrual rates for earlier ages.
} 
the pension plans associated with retiree coverage also provide the strongest incentives for early retirement. Failing to capture this link will lead the econometrician to overstate the effect of retiree coverage on retirement.

\subsection{Preference Index}

In order to better measure preference heterogeneity in the population (and how it is correlated with health insurance), we estimate a person's "willingness" to work using three questions from the first (1992) wave of the HRS. The first question asks the respondent the extent to which he agrees with the statement, "Even if I didn't need the money, I would probably keep on working." The second question asks the respondent, "When you think about the time when you will retire, are you looking forward to it, are you uneasy about it, or what?" The third question asks, "How much do you enjoy your job?"

To combine these three questions into a single index, we regress wave 5-7 (survey year 20002004) participation on the response to the three questions along with polynomials and interactions of all the state variables in the model: age, health status, wages, wealth, and AIME, medical expenses, and health insurance type. Multiplying the numerical responses to the three questions by their respective estimated coefficients and summing yields an index. We then discretize the index into three values: high, for the top $50 \%$ of the index for those working in wave 1 ; low, for the bottom $50 \%$ of the index for those working in wave 1 ; and out for those not working in wave 1 .

\subsection{Wages}

Recall from equation (11) that $\ln W_{t}=\alpha \ln \left(N_{t}\right)+W\left(H_{t}, t\right)+\omega_{t}$. Following Aaronson and French, (2004), we set $\alpha=0.415$, which implies that a $50 \%$ drop in work hours leads to a $25 \%$

drop in the offered hourly wage. This is in the middle of the range of estimates of the effect of hours worked on the offered hourly wage.

We estimate $W\left(H_{t}, t\right)$ using the methodology described in section 5.3.

Estimates that include the validation sample show, however, that those with retiree coverage have the highest pension accrual rates in their early and middle 50 s. 
The parameters for the idiosyncratic process $\omega_{t},\left(\sigma_{\eta}^{2}, \rho_{W}\right)$ are estimated by French, (2005). The results indicate that the autocorrelation coefficient $\rho_{W}$ is 0.977 ; wages are almost a random walk. The estimate of the innovation variance $\sigma_{\eta}^{2}$ is 0.0141 ; one standard deviation of an innovation in the wage is $12 \%$ of wages.

\subsection{Remaining Calibrations}

We set the interest rate $r$ equal to 0.03. Spousal income depends upon an age polynomial and health status. Health status and mortality both depend on previous health status interacted with an age polynomial.

\section{Data Profiles and Initial Conditions}

\subsection{Data Profiles}

Figure 4 puts some of the labor market behavior that we seek to explain in relation to the health insurance status. By correctly estimating the structural parameters linking the two (and the broader environment), we will be able to predict the effects of the ACA on exit rates and participation. The top panel of Figure 4 shows empirical job exit rates conditional on the initially observed health insurance type. Recall that Medicare should provide the largest labor market incentives for workers that have tied health insurance. If these people place a high value on health insurance, they should either work until age 65, when they are eligible for Medicare, or they should work until age 63.5 and use COBRA coverage as a bridge to Medicare. The job exit profiles in the top panel provide some evidence that those with tied coverage do tend to work until age 65 . While the age-65 job exit rate is similar for those whose health insurance type is tied $(17 \%)$, retiree $(17 \%)$, or non-group (14\%), those with retiree coverage have higher exit rates at $62(20 \%)$ than those with tied (15\%) or non-group (13\%). At all ages other than 65, those with retiree coverage have higher job exit rates than those with tied coverage, often much higher. These values for the 1940s cohort are very similar to those reported by French and Jones, (2011) for the 1931-1936 cohort.

The low job exit rates before age 65 and the relatively high job exit rates at age 65 for those 
with tied coverage suggests that some people with tied coverage are working until age 65, when they become eligible for Medicare. On the other hand, job exit rates for those with tied coverage are lower than those with retiree coverage for every age other than 65 , and are not much higher at age 65. This suggests that differences in health insurance coverage may not be the only reason for the differences in job exit rates.

The bottom panel of Figure 4 presents the employment rates that result from these exit rates and the initial employment rates. It is not surprising that the non-group category has the lowest participation rates already at the beginning since it includes Medicare and Medicaid recipients who are eligible for SSDI because they are unable to work. While the initially high employment rate of those with tied coverage is not surprising (recall that these individuals must have been working in the previous period to have access to their employers group plan, either directly or through COBRA coverage), it stays consistently higher than any of the other two groups. Conversely, the high exit rates of those with retiree coverage lead to similar levels of participation as those without access to group insurance already in individuals' mid-sixties. Figure 5 shows that the preference index described in Section 6.7 has great predictive power. At age 65 , participation rates are $60 \%$ for those with an index of high, $45 \%$ for those with an index of low, and $9 \%$ for those with an index of out.

\subsection{Initial Conditions}

Each artificial individual in our model begins its simulated life with the state vector of an individual born in the 1940s, aged 51-60 when first observed in the data. Table 7 summarizes this initial distribution.

Table 7 shows that asset levels are highest for individuals with tied health insurance and almost half of that in the non-group category, individuals with retiree coverage being somewhere in the middle. A reason for the difference between the tiedand retiree groups may be that the latter tend to have more generous pension plans. Pension wealth in both groups is far higher than in the non-group category in fact, the median individual without access to employer-provided insurance does not have any pension wealth at all. Individuals in the non-group category are also more likely to be in bad health, and not surprisingly, less likely to be working. In contrast, 
individuals with tied coverage have high values of the preference index, suggesting that their delayed retirement reflects differences in preferences as well as in incentives.

Individuals with retiree coverage have the lowest medical expenses, both in terms of total expenditure and in terms of out-of-pocket costs, where those in the non-group category are similar. These latter individuals have much higher total expenditure, which is - at least in part - a reflection of their poor health.

A key step for being able to predict the effects of the ACA and a major innovation relative to French and Jones, (2011) is to adequately break up the non-group category according to eligibility for Medicare through SSDI and Medicaid through SSI and the choice between private coverage and staying uninsured for those who are not eligible. Table 8 displays the initial distribution for individuals without employer-provided coverage, i.e., everybody in the respective column of Table 7 . Individuals who purchase private insurance are very similar to individuals in the tied and retiree categories along many dimensions they are quite healthy, often married, likely to be and working and putting in long hours if doing so, and they have high values of the preference index. However, they have more assets, which presumably compensate for their lower pension wealth and higher medical expenses.

Conversely, the uninsured are in worse health, have lower values of the preference index, are less likely to be working and they are more often single. Their health care costs are low and on average, they have less than a fifth of the wealth and less than half of the pension wealth of those who purchase private insurance.

People who are eligible for Medicare through SSDI are in poor health by definition. Only $11 \%$ of them are working and those individuals are mostly doing part-time work only, reflecting overall incentives. They are less likely to be married and their wealth variables are comparable to those of the uninsured. The last column shows, not surprisingly, that Medicaid recipients are poorer on average and fare worse on almost all socio-demographic dimensions. Their low out-of-pocket medical expenditures reflect the generosity of Medicaid, the high total costs are an artefact of our imputation procedure that inverts the budget sets using the parameters shown in 4 In sum, it is clear that the uninsured are worse off along many dimensions than those who purchase private insurance and that the Medicare/Medicaid programs might have 
important incentive effects for this group well before age 65 . 


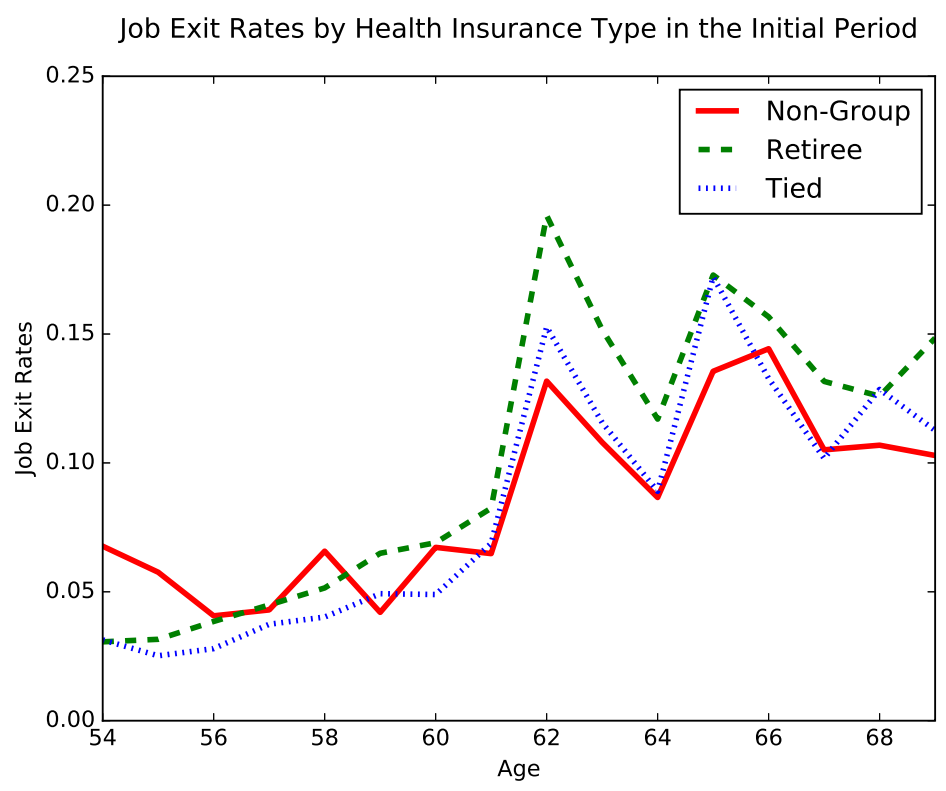

Participation Rates by Health Insurance Type in the Initial Period

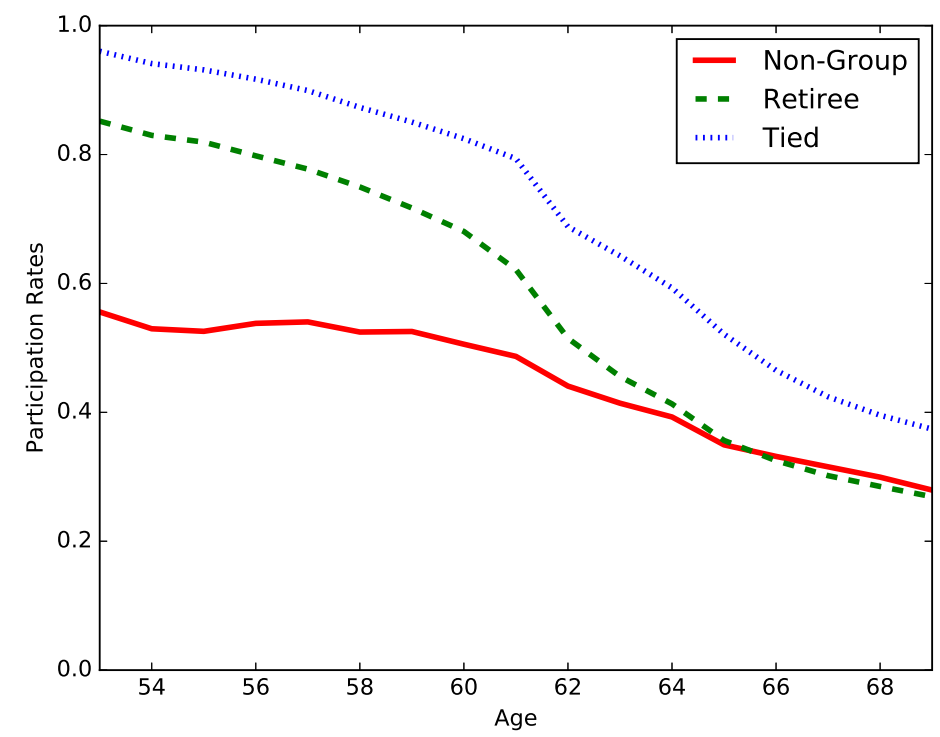

Figure 4: Job Exit and Participation (Employment) Rates, Data 


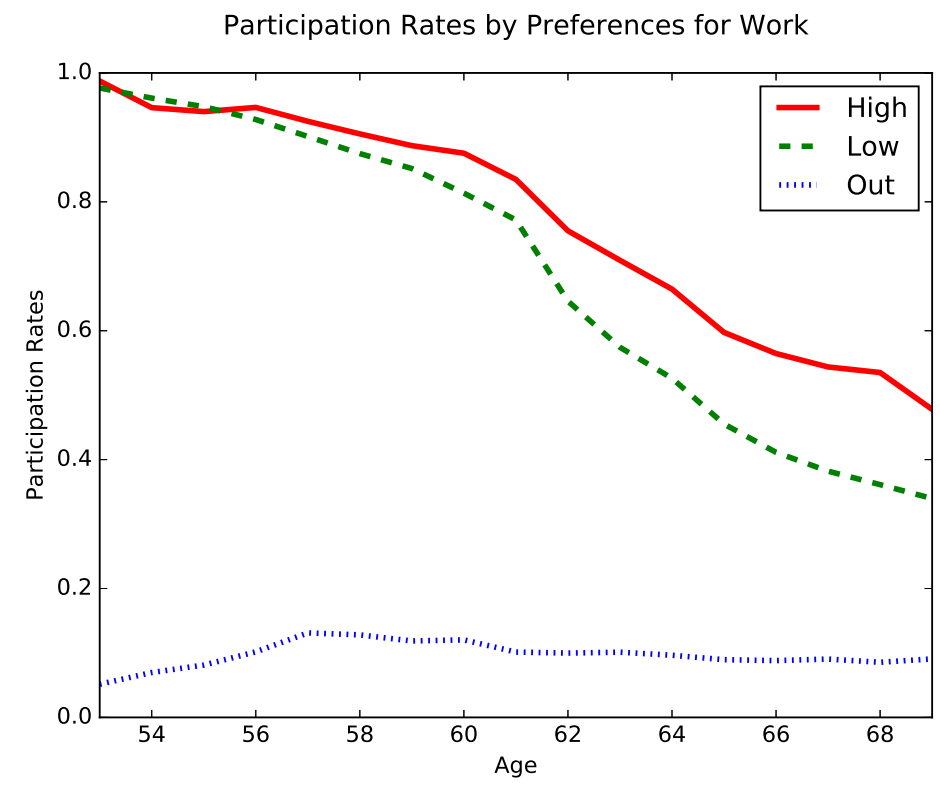

Figure 5: Participation (Employment) Rates by Preference Index, Data 


\begin{tabular}{|c|c|c|c|c|}
\hline Variable & Statistic & Retiree & Tied & $\begin{array}{l}\text { Employer } \\
\text { Coverage }\end{array}$ \\
\hline \multirow[t]{3}{*}{ Age } & Mean & 53.2 & 53.5 & 53.5 \\
\hline & Median & 52.0 & 53.0 & 53.0 \\
\hline & Std.Dev. & 2.1 & 2.1 & 2.2 \\
\hline \multirow[t]{3}{*}{ AIME / 1000} & Mean & 15.8 & 17.0 & 11.1 \\
\hline & Median & 16.9 & 17.4 & 7.7 \\
\hline & Std.Dev. & 7.7 & 8.3 & 13.4 \\
\hline \multirow[t]{3}{*}{ Assets / 1000} & Mean & 317.6 & 489.4 & 253.9 \\
\hline & Median & 161 & 192.7 & 40.7 \\
\hline & Std.Dev. & 569.2 & 990.1 & 717.6 \\
\hline \multirow[t]{3}{*}{ Pension Wealth / 1000} & Mean & 199.0 & 162.1 & 25.0 \\
\hline & Median & 77.1 & 57.2 & 0.0 \\
\hline & Std.Dev. & 293.9 & 318.3 & 90.5 \\
\hline Works & Fraction & 0.86 & 0.95 & 0.58 \\
\hline \multirow[t]{3}{*}{ Wage if working } & Mean & 25.5 & 29.5 & 20.1 \\
\hline & Median & 22.9 & 25.9 & 15.2 \\
\hline & Std.Dev. & 13.5 & 16.6 & 14.5 \\
\hline \multirow[t]{3}{*}{ Hours if working } & Mean & 240.02 & 2469.7 & 2283.4 \\
\hline & Median & 2200.0 & 2340.0 & 2080.0 \\
\hline & Std.Dev. & 654.5 & 629.3 & 942.1 \\
\hline \multirow[t]{3}{*}{ Total health care costs / 1000} & Mean & 16.26 & 22.69 & 29.33 \\
\hline & Median & 8.39 & 11.47 & 2.61 \\
\hline & Std.Dev. & 21.87 & 29.00 & 134.80 \\
\hline \multirow[t]{3}{*}{ OOP health care costs / 1000} & Mean & 4.09 & 5.37 & 4.03 \\
\hline & Median & 2.16 & 2.73 & 1.34 \\
\hline & Std.Dev. & 12.00 & 7.76 & 11.30 \\
\hline Good health & Fraction & 0.82 & 0.88 & 0.57 \\
\hline Pref. index $=0$ & Fraction & 0.14 & 0.05 & 0.42 \\
\hline Pref. index $=1$ & Fraction & 0.77 & 0.88 & 0.48 \\
\hline Pref. index $=2$ & Fraction & 0.09 & 0.07 & 0.10 \\
\hline Married & Fraction & 0.85 & 0.8 & 0.62 \\
\hline Not married & Fraction & 0.15 & 0.2 & 0.38 \\
\hline Observations & Count & 1081 & 561 & 500 \\
\hline
\end{tabular}

Table 7: Summary Statistics for the Initial Distribution

Note: Source: HRS data. Total health care costs are imputed from out-of-pocket health care costs by inverting the budget sets described in 6.5, estimated off MEPS data. The column "No Employer Coverage" reflects individuals in the non-group category. 


\begin{tabular}{|c|c|c|c|c|c|}
\hline Variable & Statistic & $\begin{array}{r}\text { Private } \\
\text { Non-Group }\end{array}$ & Uninsured & Medicare & $\begin{array}{r}\text { Medicare- } \\
\text { Medicaid }\end{array}$ \\
\hline \multirow[t]{3}{*}{ Age } & Mean & 53.5 & 53.3 & 53.7 & 54.1 \\
\hline & Median & 53.0 & 53.0 & 54.0 & 54.0 \\
\hline & Std.Dev. & 2.2 & 2.1 & 2.4 & 2.2 \\
\hline \multirow{3}{*}{ AIME / 1000} & Mean & 13.6 & 9.5 & 13.4 & 11.6 \\
\hline & Median & 12.8 & 7.4 & 7.8 & 5.4 \\
\hline & Std.Dev. & 7.5 & 7.0 & 18.3 & 26.7 \\
\hline \multirow[t]{3}{*}{ Assets / 1000} & Mean & 768.7 & 144.5 & 136 & 24.1 \\
\hline & Median & 375.6 & 35.4 & 41.2 & 1.4 \\
\hline & Std.Dev. & 1341.8 & 347.5 & 322.2 & 170.1 \\
\hline \multirow[t]{3}{*}{ Pension Wealth / 1000} & Mean & 50.1 & 21.9 & 21.1 & 4.0 \\
\hline & Median & 0.3 & 0.0 & 0.0 & 0.0 \\
\hline & Std.Dev. & 130.7 & 87.8 & 58.6 & 15.5 \\
\hline Works & Fraction & 0.87 & 0.7 & 0.11 & 0.09 \\
\hline \multirow[t]{3}{*}{ Wage if working } & Mean & 25.8 & 17.3 & 18.5 & 24.8 \\
\hline & Median & 21 & 13.3 & 9.9 & 16.7 \\
\hline & Std.Dev. & 16.5 & 12.5 & 15.9 & 18.6 \\
\hline \multirow[t]{3}{*}{ Hours if working } & Mean & 2507.0 & 2240.0 & 1261.1 & 1505.7 \\
\hline & Median & 2184.0 & 2080.0 & 1040.0 & 1742.0 \\
\hline & Std.Dev. & 954.9 & 907.0 & 799.0 & 740.1 \\
\hline \multirow[t]{3}{*}{ Total health care costs / 1000} & Mean & 24.93 & 4.93 & 24.37 & 132.58 \\
\hline & Median & 10.30 & .90 & 1.97 & 39.04 \\
\hline & Std.Dev. & 29.36 & 21.32 & 51.94 & 335.89 \\
\hline \multirow[t]{3}{*}{ OOP health care costs / 1000} & Mean & 6.74 & 3.60 & 4.41 & 1.37 \\
\hline & Median & 3.94 & 0.90 & 1.97 & 0.25 \\
\hline & Std.Dev. & 6.38 & 14.43 & 6.95 & 2.06 \\
\hline Good health & Fraction & 0.87 & 0.69 & 0.0 & 0.17 \\
\hline Pref. index 0 & Fraction & 0.13 & 0.3 & 0.89 & 0.91 \\
\hline Pref. index 1 & Fraction & 0.75 & 0.57 & 0.08 & 0.09 \\
\hline Pref. index 2 & Fraction & 0.13 & 0.13 & 0.03 & 0 \\
\hline Married & Fraction & 0.75 & 0.65 & 0.56 & 0.34 \\
\hline Not married & Fraction & 0.25 & 0.35 & 0.44 & 0.66 \\
\hline Observations & Count & 102 & 265 & 63 & 70 \\
\hline
\end{tabular}

Table 8: Summary Statistics For the Initial Distribution of Individuals without Employer-Provided Health Insurance

Note: Source: HRS data. Individuals included in this table are those in the column called "No Employer Coverage" in Table 7. Total health care costs are imputed from out-of-pocket health care costs by inverting the budget sets described in 6.5, estimated off MEPS data. 


\section{Conclusion}

The Affordable Care Act (ACA) is the most significant reform to the health care sector in since the 1960s. The ACA's provisions fall into four main categories: (1) an expansion of Medicaid; (2) an overhaul of private non-group insurance, including community rating, coverage standards, the introduction of exchanges, subsidies, and purchase mandates; (3) a mandate for large employers to offer health insurance coverage, and subsidies for smaller employers; (4) miscellaneous provisions including reforms to coverage standards, the tax code, and the management of Medicare.

In this paper, we consider the following two sets of provisions. First, the ACA expands Medicaid eligibility for low-income households younger than 65. Prior to the ACA, low-income households nearing retirement qualified for Medicaid only if they were disabled. Moreover, under the ACA Medicaid applicants no longer face an asset test, meaning that they can qualify for Medicaid even if they hold significant wealth. The ability to carry wealth into retirement should make Medicaid more attractive for older workers. Overall, the Medicaid expansion could either increase or reduce labor supply by the elderly. Perhaps most likely, fewer people will work, as they can now qualify for Medicaid if they retire.

The second set of provisions involves non-group insurance. The ACA establishes exchanges where households without group coverage can purchase insurance. The policies offered on these exchanges must meet coverage standards, and they must be community-rated, i.e., insurers cannot price-discriminate by health. The ACA also requires uninsured households ineligible for Medicaid to purchase insurance, provides tax subsidies for most purchases, and levies penalties on those not complying. These changes should significantly alter the customer base and actuarial costs in the non-group market. Although the subsidies will allow most households to purchase non-group insurance more cheaply, healthy and/or lightly subsidized individuals may see their premiums rise. Because many workers lose their employer-provided insurance after they leave their job (and the COBRA buy-in period expires), changes in the price of non-group insurance may change their retirement decisions. Because most people will be able to buy non-group health insurance more cheaply, early retirement will probably increase. Balancing against this, the subsidies provided under the ACA will allow uninsured low-income 
workers to purchase cheap insurance in the non-group market. Prior to the ACA these people may have used default on medical bills as a substitute for health insurance. However, default is a good substitute for insurance only when income and assets are low. Acquiring health insurance may encourage these workers to work and save more (Hsu, 2013).

Our goal is to assess the quantitative importance of these effects. To do this, we extend the structural labor supply and retirement model in French and Jones, (2011) to account for these reforms. We extend their model by adding in a much more detailed model of medical spending and insurance. We model explicitly how different types of health insurance plans affect the premiums and coinsurance rates that households face. We use data from the Health and Retirement Study (HRS) and the Medical Expenditure Panel Survey (MEPS) to estimate the structural model. We use the MEPS data to measure current medical expenditures, as well as who pays for these expenditures (out-of-pocket, private insurance, Medicaid, etc.). We use this information to estimate a dynamic programming model of labor supply and retirement behavior where individuals face realistic medical expense risk. Upon estimating the model, we conduct counterfactual experiments, where we modify the premia and co-insurance rates, net of subsidies and penalties, that households face.

We construct a retirement model that includes health insurance, uncertain medical costs, a savings decision, a non-negativity constraint on assets and a government-provided consumption floor.

We present evidence that those who cannot keep their employer-provided health insurance when they leave their job tend to remain on their job until age 65 . Those who can maintain their insurance after they leave their job tend to exit the labor market earlier. This provides evidence that access to health insurance reduces labor supply. Interestingly, however, recent evidence on Medicaid expansions suggests small if any disemployment effect of Medicaid (Levy, Buchmueller, and Nikpay, 2015).

We show differences in both total and out-of-pocket medical spending prior to the enactment of the ACA. We show that average total medical spending in MEPS is high for all groups. Perhaps surprisingly, those with no health insurance do not spend much more out-of-pocket than those who private insurance. Those uninsured receive health care through a variety 
of sources such as worker's compensation and default on medical bills, which we refer to as a "consumption floor", which protects low income individuals against catastrophic medical spending. Those who appear to have the highest resources appear to be those who pay the most for health care, consistent with the view that those with low resources are covered by the consumption floor, whereas those with high resources face the most medical expense risk and might have the largest labor supply responses. We choose the consumption floor to match these, and other facts. Thus we model the ACA as a change in government insurance provisions rather than the provision of insurance where none existed before. 


\section{References}

Aaronson, Daniel and Eric French (2004). "The Effect of Part-Time Work on Wages: Evidence from the Social Security Rules". In: Journal of Labor Economics 22.2, pp. 329-352.

Blau, David and Donna Gilleskie (2006). "Health Insurance and Retirement of Married Couples". In: Journal of Applied Econometrics 21.7, pp. 935-953.

Blau, David M. and Donna B. Gilleskie (2008). "The Role of Retiree Health Insurance in the Employment Behavior of Older Men". In: International Economic Review 49.2, pp. 475514.

Brown, Jeff and Amy Finkelstein (2008). "The Interaction of Public and Private Insurance: Medicaid and the Long Term Care Insurance Market". In: American Economic Review 98.5, pp. 837-880.

Buchmueller, Thomas and John DiNardo (2002). "Did Community Rating Induce an Adverse Selection Death Spiral? Evidence from New York, Pennsylvania, and Connecticut". In: American Economic Review 92.1, pp. 280-294.

Center on Budget and Policy Priorities (2015). "Key Facts: Cost-Sharing Reductions". http: //www . healthreformbeyond thebasics . org/cost-sharing-charges - in-marketplacehealth-insurance-plans-part-2/.

Centers for Medicare and Medicaid Services (2014). "Medicare Secondary Payer". https: //www . cms . gov/Medicare/Coordination- of -Benefits-and-Recovery/Coordinationof - Benefits - and - Recovery - Overview / Medicare - Secondary - Payer / Medicare Secondary-Payer .html.

Cogan, John (1981). "Fixed Costs and Labor Supply". In: Econometrica 49.4, pp. 945-963.

Committee On Ways And Means, U.S.House of Representatives (various years). "Green Book". http://greenbook. waysandmeans.house.gov/.

Congressional Budget Office (2015). "Budgetary and Economic Effects of Repealing the Affordable Care Act". https://www.cbo.gov/publication/50252.

De Nardi, Mariacristina, Eric French, and John Bailey Jones (2010). "Why Do the Elderly Save? The Role of Medical Expenses". In: Journal of Political Economy 118.1, pp. 39-75.

De Nardi, Mariacristina, Eric French, John Bailey Jones, and Jeremy McCauley (forthcoming). "Medical Spending on the U.S. Elderly". In: Fiscal Studies.

De Nardi, Mariacristina (2004). "Wealth Inequality and Intergenerational Links". In: Review of Economic Studies 71.3, pp. 743-768.

Fernandez, Bernadette (2014). "Health Insurance Premium Credits in the Patient Protection and Affordable Care Act (ACA)". Congressional Research Service, Library of Congress R41137.

French, Eric (2005). "The Effects of Health, Wealth, and Wages on Labour Supply and Retirement Behaviour". In: Review of Economic Studies 72.2, pp. 395-427. 
French, Eric and John Bailey Jones (2004). "On the Distribution and Dynamics of Health Care Costs". In: Journal of Applied Econometrics 19.6, pp. 705-721.

- (2011). "The Effects of Health Insurance and Self-Insurance on Retirement Behavior". In: Econometrica 79.3 , pp. 693-732.

Gourinchas, Pierre-Olivier and Jonathan A. Parker (2002). "Consumption over the Life Cycle". In: Econometrica 70.1, pp. 47-89.

Gruber, Jonathan and Brigette Madrian (1996). "Health Insurance and Early Retirement: Evidence from the Availability of Continuation Coverage". In: Advances in the Economics of Aging. Ed. by David A. Wise. Chicago: University of Chicago Press, pp. 115-143.

Gustman, Alan and Thomas Steinmeier (2005). "The Social Security early entitlement age in a structural model of retirement and wealth". In: Journal of Public Economics 89.

Harris, Edward and Shannon Mok (2015). "How CBO Estimates the Effects of the Affordable Care Act on the Labor Market". Congressional Budget Office Working Paper 2015-09.

Heckman, James J. and Burton Singer (1984). "A Method for Minimizing the Impact of Distributional Assumptions in Econometric Models for Duration Data". In: Econometrica 52.2, pp. 271-320.

Herring, Bradley and Mark V. Pauly (2006). "The Effect of State Community Rating Regulations on Premiums and Coverage in the Individual Health Insurance Markets". NBER Working Paper 12504.

Hsu, Minchung (2013). "Health Insurance and Precautionary Saving: A Structural Analysis". In: Review of Economic Dynamics 16.3, pp. 511-526.

Hubbard, R. Glenn, Jonathan S. Skinner, and Stephen P. Zeldes (1994). "The Importance of Precautionary Motives in Explaining Individual and Aggregate Saving". In: CarnegieRochester Conference Series on Public Policy 40, pp. 59-125.

- (1995). "Precautionary Saving and Social Insurance". In: Journal of Political Economy 103.2, pp. 360-399.

Jones, John and Yue Li (2016). "The Effects of Collecting Income Taxes on Social Security Benefits".

Kahn, James (1988). "Social Security, liquidity, and early retirement". In: Journal of Public Economics 35.1, pp. 97-117.

Keane, Michael P. and Kenneth I. Wolpin (1997). "The Career Decisions of Young Men". In: Journal of Political Economy 105.3, pp. 473-522.

Levy, Helen, Thomas Buchmueller, and Sayeh Nikpay (2015). "The Effect of Health Reform on Retirement". MRRC Working Paper.

Marken, Stephanie (2016). "U.S. Uninsured Rate at New Low of $10.9 \%$ in Third Quarter". http : / / ww . gallup . com/poll/196193/uninsured-rate-new-low-third-quarter . aspx?version=print. 
Mulligan, Casey B. (2013). "Average Marginal Labor Income Tax Rates under the Affordable Care Act". NBER Working Paper 19365.

Olsen, Anya and Kathleen Romig (2013). "Modeling Behavioral Responses to Eliminating the Retirement Earnings Test". In: Soc. Sec. Bull. 73, p. 39.

Pashchenko, Svetlana and Ponpoje Porapakkarm (forthcoming). "Medical Spending in the US: Facts from the Medical Expenditure Panel Survey Dataset". In: Fiscal Studies.

Rust, John and Christopher Phelan (1997). "How Social Security and Medicare Affect Retirement Behavior in a World of Incomplete Markets". In: Econometrica 65.4, pp. 781831.

Scholz, John Karl and Ananth Seshadri (2013). "Health Insurance and Retirement Decisions". Michigan Retirement Research Center Research Paper 2013-292.

Sing, Merrile, Jessica S. Banthin, Thomas M. Selden, Cathy A. Cowan, and Sean P. Keehan (2006). "Reconciling Medical Expenditure Estimates from the MEPS and NHEA, 2002". In: Health Care Financing Review 28.1, pp. 25-40.

The Henry J. Kaiser Family Foundation (2013). "Summary of the Affordable Care Act". http: //kff .org/health-reform/fact-sheet/summary-of-the-affordable-care-act/.

van der Klaauw, Wilbert and Kenneth I. Wolpin (2008). "Social Security and the Retirement and Savings Behavior of Low-Income Households". In: Journal of Econometrics 145.1-2, pp. 21-42. 


\section{A Cast of Characters}

\begin{tabular}{|c|c|c|c|}
\hline \multicolumn{2}{|c|}{ Preference Parameters } & \multicolumn{2}{|c|}{ Health-related Parameters } \\
\hline$\gamma$ & consumption weight & $H_{t}$ & health status \\
\hline$\beta$ & time discount factor & $Z_{t}$ & total medical expenses \\
\hline$\nu$ & coefficient of RRA, utility & $I_{t}$ & employer-provided HI type \\
\hline$\theta_{B}$ & bequest weight & $z(\cdot)$ & mean shifter, logged medical expenses \\
\hline$\kappa$ & bequest shifter & $\sigma(\cdot)$ & volatility shifter, logged medical expenses \\
\hline$C_{\min }$ & consumption floor & & idiosyncratic medical expense shock \\
\hline$L$ & leisure endowment & $\zeta_{t}$ & persistent medical expense shock \\
\hline$\phi_{H}$ & leisure cost of bad health & & innovation, persistent shockk \\
\hline$\phi_{P t}$ & fixed cost of work & & autocorrelation, persistent shock \\
\hline$\phi_{P 0}$ & fixed cost, intercept & $\sigma_{\epsilon}^{2}$ & innovation variance, persistent shock \\
\hline$\phi_{P 1}$ & fixed cost, time trend & & transitory medical expense shock \\
\hline$\phi_{R E}$ & re-entry cost & & variance, transitory shock \\
\hline & & $\dot{M}_{t}$ & out-of-pocket medical expenses \\
\hline \multicolumn{2}{|c|}{ Decision Variables } & \multicolumn{2}{|c|}{ Wage-related Parameters } \\
\hline$C_{t}$ & consumption & & hourly wage \\
\hline$N_{t}$ & hours of work & $W(\cdot)$ & mean shifter, logged wages \\
\hline$L_{t}$ & leisure & & coefficient on hours, logged wages \\
\hline$P_{t}$ & participation & & idiosyncratic wage shock \\
\hline$A_{t}$ & assets & $\rho_{W}$ & autocorrelation, wage shock \\
\hline$B_{t}$ & Social Security application & & innovation, wage shock \\
\hline$I_{t}^{+}$ & health insurance type & $\sigma_{\eta}^{2}$ & innovation variance, wage shock \\
\hline \multicolumn{2}{|c|}{ Financial Variables } & \multicolumn{2}{|c|}{ Miscellaneous } \\
\hline$Y(\cdot)$ & after-tax income & $s_{t}$ & survival probability \\
\hline$\tau$ & tax parameter vector & pref & discrete preference index \\
\hline$r$ & real interest rate & $X_{t}$ & state vector, worker's problem \\
\hline$y s_{t}$ & spousal income & $\lambda(\cdot)$ & compensating variation \\
\hline$\Upsilon$ & spousal income indicator & $S P$ & spouse indicator \\
\hline$s s_{t}$ & Social Security income & $T$ & number of years in GMM criterion \\
\hline $\begin{array}{l}A I M E_{t} \\
p b_{t}\end{array}$ & $\begin{array}{l}\text { Social Security wealth } \\
\text { pension benefits }\end{array}$ & & \\
\hline
\end{tabular}

Table 9: Variable Definitions, Main Text 


\section{A.1 Health Insurance}

Table 10 presents the health insurance state transitions that we allow for. These transitions depend on work status, age, and whether the individual is eligibile for the DI (Disability Insurance) or SSI (Supplemental Seccurity Income) programs. The last column of the table presents the payment sources and, if applicable, whether the individual has the choice between purchasing private non-group insurance and staying uninsured. We allow for the most common health insurance transitions observed in our data, and do not allow for transitions that are so uncommon empirically that we are unable to estimate the budget set parameters for these groups. Hence, there are a few things to note about Table 10:

- People will hold on to Retiree Health Insurance until their death, unless they become eligible for Medicaid by falling into the categorically needy category. Although in principle individuals could keep employer provided coverage while drawing Medicaid, our estimated insurance premia and co-insurance rates suggest that Medicaid alone is less expensive than Medicaid plus employer provided coverage since Medicaid pays for the same care private insurance pays for, but Medicaid does not pay the private insurance premia. Furthermore. eligibility requirements for Medicaid are so strict that these people would have to spend a very large fraction of their income on Retiree insurance premia. Reassuringly, very few people hold both empolyer provided and Medicaid insurance simulataneously.

- Closely related to the above case, individuals loose their Tied coverage if they become eligible for Medicaid. Again, very few people in the data simultaneously hold both employer provided insurance and Medicaid. Being eligible for Medicaid while working requires a very low wage or a very low number of hours, and individiuals with low hours or wages usually do not receive employer-provided coverage.

- Before age 65 , the combination of Tied insurance and Medicare is impossible in the model because of individuals must be out of work for one year to be eligible for Disability Insurance.

- Everybody becomes eligible for Medicare at age 65. We do not model supplemental coverage. Hence, the "Uninsured" and "Private Non-Group" categories disappear after age 65. The same holds true for standalone Medicaid. 
- Disabled people younger than age 65 can receive Medicare, Medicaid, or both depending on eligibility for DI and SSI. DI beneficiaries receive Medicare, whereas SSI beneficiaries receive Medicaid.

To be eligible for DI one must have worked 5 of the last 10 years, and at least a total of (for a 54 year old) 8 years. Those who worked fewer years only receive SSI.

The SSI maximum benefit amount in this case is $\$ 721$. This maximum benefit is only available to those with extremely low income and assets. Those with higher income have their benefit clawed back.

So who gets both DI and SSI? It is the people whose work criteria says they can get DI, but their benefit is below the threshold. The DI benefit is calculated the same way as the Social Security benefit, using AIME, which is our state variable. So if their DI benefit would be $\$ 500$, then they would get at $\$ 221$ SSI benefit. This would make them eligible for both Medicaid and Medicare.

We approximate these rules as follows:

- We assume that everybody who becomes disabled meets the work requirements for DI

- Disabled individuals who do not meet the categorically needy criteria, are automatically DI/Medicare,

- For disabled individuals who are categorically needy, we use the model to calculate the DI benefit using AIME. If the benefit is over $\$ 721$, they receive only Medicare. Else, they receive Medicare and Medicaid if their DI benefit is over $\$ 400$ and only Medicaid if it is below this value 
Table 10: Health Insurance State Transitions

\begin{tabular}{|c|c|c|c|c|c|c|}
\hline$I_{t-1}$ & $P_{t-1}=1$ & $I_{t}$ & $t$ & $\begin{array}{c}H_{t} \\
=\text { disabled }\end{array}$ & $\begin{array}{l}\text { cat. needy } \\
Y_{t}, A_{t}\end{array}$ & $\begin{array}{l}\text { Payment } \\
\text { sources }\end{array}$ \\
\hline \multirow[t]{5}{*}{ retiree } & . & retiree & $<65$ & no & . & $\mathrm{R}$ \\
\hline & & & & yes & no & $\mathrm{R}+\mathrm{MC}$ \\
\hline & & & $\geq 65$ & . & no & $\mathrm{R}+\mathrm{MC}$ \\
\hline & & non-group & $<65$ & yes & yes & $(\mathrm{MC}+) \mathrm{MA}$ \\
\hline & & & $\geq 65$ & . & yes & $\mathrm{MC}+\mathrm{MA}$ \\
\hline \multirow[t]{8}{*}{ tied } & yes & tied & $<65$ & no & . & $\mathrm{T}$ \\
\hline & & & $\geq 65$ & . & no & $\mathrm{T}+\mathrm{MC}$ \\
\hline & & non-group & $\geq 65$ & . & yes & $\mathrm{MC}+\mathrm{MA}$ \\
\hline & no & non-group & $<65$ & no & & $\{\mathrm{U}, \mathrm{P}\}$ \\
\hline & & & & yes & no & $\mathrm{MC}$ \\
\hline & & & & & yes & $(\mathrm{MC}+) \mathrm{MA}$ \\
\hline & & & $\geq 65$ & . & no & $\mathrm{MC}$ \\
\hline & & & & & yes & $\mathrm{MC}+\mathrm{MA}$ \\
\hline \multirow[t]{5}{*}{ non-group } & . & non-group & $<65$ & no & . & $\{\mathrm{U}, \mathrm{P}\}$ \\
\hline & & & & yes & no & $\mathrm{MC}$ \\
\hline & & & & & yes & $(\mathrm{MC}+) \mathrm{MA}$ \\
\hline & & & $\geq 65$ & . & no & $\mathrm{MC}$ \\
\hline & & & & & yes & $\mathrm{MC}+\mathrm{MA}$ \\
\hline
\end{tabular}

Legend for payment sources:

$\begin{array}{lll}\mathrm{R} & \text { Employer's retiree plan } & P_{t}=1 \text { if working } \\ \mathrm{T} & \text { Employer's tied plan } & I_{t}=\text { insurance type } \\ \mathrm{U} & \text { Uninsured } & \\ \mathrm{P} & \text { Privately purchased insurance plan } & \\ \mathrm{MC} & \text { Medicare } & \\ \mathrm{MA} & \text { Medicaid } & \end{array}$


Individuals' insurance status determines how total health care cost $Z_{t}$ translate into out-ofpocket expenditures $M_{t}$. These expenditures include insurance premia and expenses covered by the consumption floor, they are given by:

$$
\begin{aligned}
M_{t} & =\operatorname{premium}\left(I_{t}^{+}, t, P_{t}, \widehat{Z}_{t}, S P_{t}\right)+\operatorname{copay}\left(I_{t}^{+}, Z_{t}\right) \\
\widehat{Z}_{t} & =\mathbb{E}\left[Z_{t} \mid t, H_{t}, \zeta_{t-1}\right] .
\end{aligned}
$$

where $\operatorname{premium}\left(I_{t}^{+}, t, P_{t}, \widehat{Z_{t}}, S P_{t}\right)$ is the health insurance premium; the function $\operatorname{copay}\left(I_{t}^{+}, Z_{t}\right)$ determines how much of $Z_{t}$ is assigned to the individual via co-payments and deductibles. We estimate the $\operatorname{copay}(\cdot)$-function directly from the MEPS data. The premium-function differs across insurance types as follows:

$$
\text { premium }= \begin{cases}\operatorname{premium}\left(t, P_{t}\right) & \text { if } I_{t}^{+}=\text {retiree } \\ \operatorname{premium}\left(t, P_{t}\right) & \text { if } I_{t}^{+}=\text {tied } \\ \operatorname{premium}\left(\widehat{Z}_{t}\right) & \text { if } I_{t}^{+}=\text {non-group } \cap \text { priv. plan } \\ 0 & \text { if } I_{t}^{+}=\text {non-group } \cap \text { self-insure }\end{cases}
$$

Note the premium depends on labor force participation $P_{t}$ in the retiree and tied categories because employer subsidies are typically reduced upon termination of a job. We estimate those values directly from the data. We assume that insurers in private plans use a pricing rule that is increasing more in expected costs:

$$
\operatorname{premium}\left(I_{t}^{+}=\text {non-group\& priv. plan, } t, \widehat{Z}_{t}, S P_{t}\right)=\alpha_{0}+\alpha_{1} \cdot 1\left\{S P_{t}=1\right\}+\alpha_{2} \widehat{Z}_{t}
$$

where all coefficents are positive.

After the introduction of the ACA, the premium function (18) becomes:

$$
\text { premium }= \begin{cases}\operatorname{premium}\left(t, P_{t}\right) & \text { if } I_{t}^{+}=\text {retiree } \\ \operatorname{premium}\left(t, P_{t}\right) & \text { if } I_{t}^{+}=\text {tied } \\ \operatorname{premium} t, I_{t}^{\text {subsidy }} & \text { if } I_{t}^{+}=\text {non-group \& priv. plan \& } t<65 \\ I_{t}^{\text {penalty }} & \text { if } I_{t}^{+}=\text {non-group\& uninsured \& } t<65\end{cases}
$$

The $\operatorname{copay}\left(I_{t}, Z_{t}\right)$ is age-invariant and translates total expenses $\left(Z_{t}\right)$ into out-of-pocket expenses 
using three insurance type-specific parameters: the deductible $\iota_{d}$, the coinsurance rate $\iota_{c}$, and the out-of-pocket limit $\iota_{o m}$ :

$$
\begin{aligned}
\operatorname{copay}\left(Z_{t} ; \iota_{d}, \iota_{c}, \iota_{\text {om }}\right) & =\min \iota_{\text {om }}, \quad \min \left\{\iota_{d}, Z_{t}\right\}+\iota_{c} \cdot \max \left\{Z_{t}-\iota_{d}, 0\right\} \\
& =\min \iota_{o m}, \iota_{c} Z_{t}+\left(1-\iota_{c}\right) \min \left\{\iota_{d}, Z_{t}\right\} .
\end{aligned}
$$

The estimates are shown in Table 4 in the main text. While the estimation of these parameters using non-linear least squares is standard, constructing the proper subsamples for each estimation type is not. Many households in the MEPS receive insurance from multiple payers, in a way that does not correspond directly to the insurance categories in the model, and the assignment of households to insurance categories is plagued by selection dynamics. This leads us to make several sample construction decisions:

- Because a number of Medicaid recipients over the age of 64 qualify for Medicaid through the Medically Needy provision, which requires them to spend down their income and assets on medical services, we estimate the parameters for Medicaid using data for households with heads younger than 65 .

- The Medicaid coinsurance rates are estimated using the expenditures that remain after Medicare, other government, and private insurer contributions.

- For households where Medicaid is not the primary insurance, Medicaid payments are treated as out-of-pocket costs borne by the households. This is because Medicaid is the residual payer, and in the model is applied to the costs that remain after other types of insurance have been applied.

- Many households that list Medicare or EPHI as their (sole) primary insurer receive assistance from multiple sources. We treat these payments (excluding Medicaid) as part of the coverage provided by the principal insurer.

- Because many of the self-insured have access to other government coverage, their payment histories are not representative of people without EPHI or Medicare as a whole. People without other government coverage are more likely to purchase non-group insurance. We thus expand the estimation sample for the "uninsured" to include any household younger than 65 that lacks EPHI or Medicare, and we treat costs covered by 
private non-group insurance as out-of-pocket expenditures. We view these costs as the costs households would face if they chose to self-insure.

Implicit in our approach above is the assumption that medical expenditures are exogenous. It is not clear ex ante whether this causes us to understate or overstate the importance of health insurance. On the one hand, individuals with health insurance receive better care. Our model does not capture this benefit, and in this respect understates the value of health insurance. Conversely, treating medical expenses as exogenous ignores the ability of workers to offset medical shocks by adjusting their expenditures on medical care. This leads us to overstate the consumption risk facing uninsured workers, and thus the value of health insurance. Evidence from other structural analyses suggests that our assumption of exogeneity leads us to overstate the effect of health insurance on retirement. ${ }^{14}$

\section{A.2 Timing of model decisions}

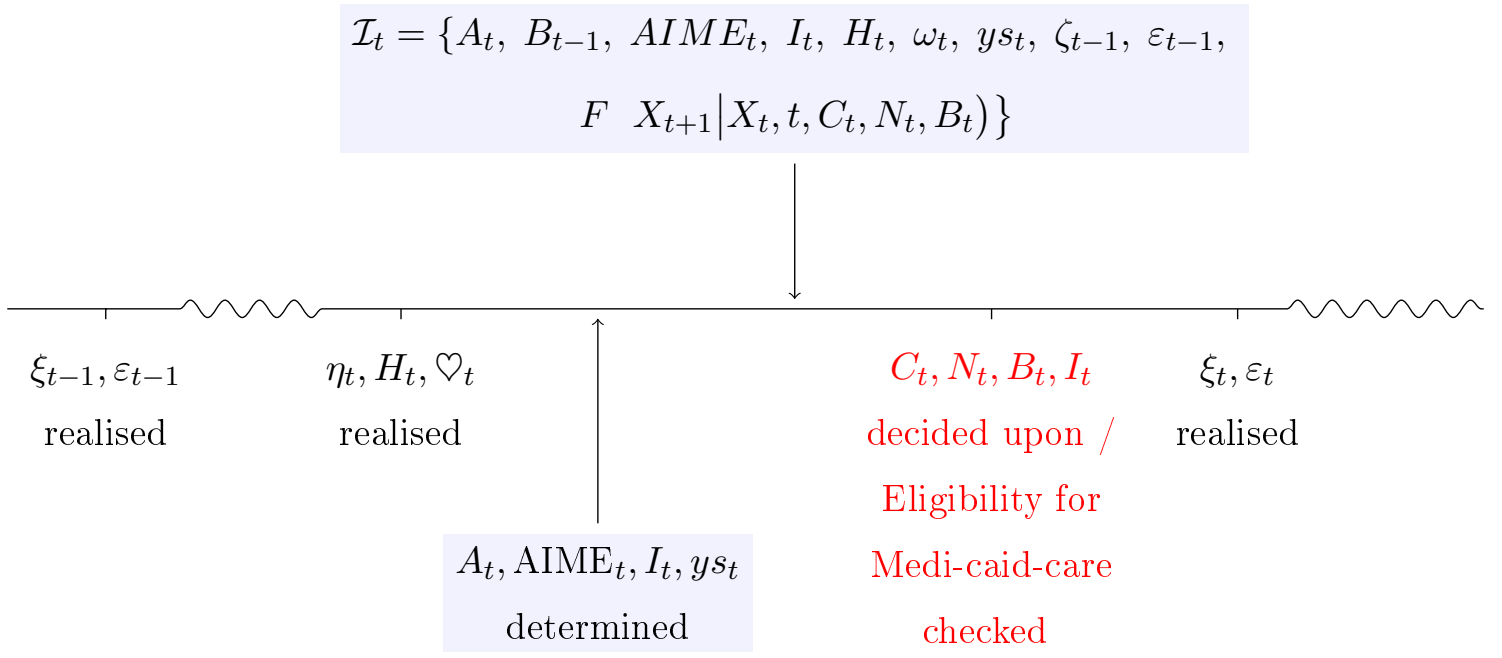

\footnotetext{
${ }^{14}$ To our knowledge, Blau and Gilleskie, (2008) is the only estimated, structural retirement study to have endogenous medical expenditures. Although Blau and Gilleskie, (2008) do not discuss how their results would change if medical expenses were treated as exogenous, they find that even with several mechanisms (such as prescription drug benefits) omitted, health insurance has "a modest impact on employment behavior among older males". De Nardi, French, and Jones, (2010) study the saving behavior of retirees. They find that the effects of reducing means-tested social insurance are smaller when medical care is endogenous, rather than exogenous. They also find, however, that even when medical expenditures are a choice variable, they are a major reason why the elderly save.
} 


\section{B Key Changes to the Model for the Situation pre-ACA (rela- tive to French and Jones, 2011)}

\section{B.1 Better Modeling of Medical Spending}

We change from:

$$
\ln M_{t}=m\left(H_{t}, I_{t}, t, P_{t}\right)+\sigma\left(H_{t}, I_{t}, t, P_{t}\right) \cdot \psi_{t}
$$

to

$$
\begin{aligned}
\ln Z_{t} & =\mu_{z}\left(H_{t}, S P_{t}, t\right)+\sigma_{z}\left(H_{t}, S P_{t}, t\right) \times \psi_{t} \\
M_{t} & =\operatorname{premium}\left(I_{t}^{+}, t, P_{t}, \widehat{Z}_{t}, S P_{t}\right)+\operatorname{copay}\left(I_{t}^{+}, Z_{t}\right), \\
\widehat{Z}_{t} & =\mathbb{E}\left[Z_{t} \mid t, H_{t}, \zeta_{t-1}\right] .
\end{aligned}
$$

where $Z_{t}$ denotes total medical expenses, $\operatorname{premium}(\cdot)$ is the health insurance premium, and the function $\operatorname{copay}(\cdot)$ determines how much of $Z_{t}$ is assigned to the individual via co-payments and deductibles.

We will estimate the parameters of these functions using MEPS.

\section{B.2 Health States and their Transitions}

Health can take on the following possible values: good, bad or disabled. Because we use both the HRS and MEPS, we exploit measures that exit in both datasets. We assign individuals a health status of "good" if self-reported health is excellent, very good or good; and we assign a health status of "bad" if self-reported health is fair or poor. "Disabled" is identified by an indicator equal to 1 if the individual is receiving Medicare and/or Medicaid benefits and is younger than 65, regardless of self reported health. We use this measure of disability because we wish to capture both the cash transfers, and even more importantly, the Medicare or Medicaid insurance received by the disabled. Unfortunately, however, this measure of disability status is missing for ages 65 and older since virtually everyone becomes Medicare eligible at age 65, and at the same age disability benefits are rolled into Social Security benefits. For this reason we assume that, conditional on age, those who are disabled or in bad health have the same distributions of medical spending, spousal income, and wages. 
Let $H_{t} \in\{0,1,2,3\}$ denote death $\left(H_{t}=0\right)$ and the 3 mutually exclusive health states of the living (disabled $=1$, bad $=2$, good $=3$, respectively). Let $x$ be a vector that includes a constant, a quadratic in age, and indicators for previous health and previous health interacted with age. Our goal is to construct the likelihood function for the transition probabilities.

Prior to age 65, we allow the disabled to have different health transition probabilities than those in in bad or good health. Because we lack data on disability after age 65, we assume that at age 65 all disabled people become either dead, in bad or good health (with transition probabilities taken from the data), then after 65 nobody becomes disabled: the health states after 65 are dead, bad health and good health. Thus we must estimate three separate health transition probability models, for before 65, at age 65, and after 65. Although this causes jumps in the probability of being in either good and bad health at age 65, our estimates suggest there is no predicted jump in mortality rates around age 65 .

Using a logit specification, we have, for $i \in\{1$ or, 3$\}, j \in\{0,1$ or 2,3$\}$,

$$
\begin{aligned}
\pi_{i j, t} & =\operatorname{Pr}\left(h_{t+1}=j \mid h_{t}=i\right) \\
& =\gamma_{i j} / \sum_{k \in\{0,1,2,3\}} \gamma_{i k}, \\
\gamma_{i 0} & \equiv 1, \quad \forall i, \\
\gamma_{1 k} & =\exp \left(x \beta_{k}\right), \quad k \in\{1,2,3\}, \\
\gamma_{2 k} & =\exp \left(x \beta_{k}\right), \quad k \in\{1,2,3\}, \\
\gamma_{3 k} & =\exp \left(x \beta_{k}\right), \quad k \in\{1,2,3\},
\end{aligned}
$$

Using a nested logit specification, we have, for $i \in\{1$ or 2,3$\}, j \in\{0,1$ or 2,3$\}$,

$$
\begin{aligned}
\pi_{i j, t} & =\operatorname{Pr}\left(h_{t+1}=j \mid h_{t}=i\right) \\
& =\gamma_{i j} / \sum_{k \in\{0,1,2,3\}} \gamma_{i k}, \\
\gamma_{i 0} & \equiv 1, \quad \forall i, \\
\gamma_{1 k} & =\exp \left(x \beta_{k}\right), \quad k \in\{1,2,3\}, \\
\gamma_{2 k} & =\exp \left(x \beta_{k}\right), \quad k \in\{1,2,3\}, \\
\gamma_{3 k} & =\exp \left(x \beta_{k}\right), \quad k \in\{1,2,3\},
\end{aligned}
$$


where $\left\{\beta_{k}\right\}_{k=0}^{3}$ are sets of coefficient vectors and of course $\operatorname{Pr}\left(h_{t+1}=0 \mid h_{t}=0\right)=1$.

The formulae above give 1-period-ahead transition probabilities, $\operatorname{Pr}\left(h_{t+1}=j \mid h_{t}=i\right)$. What we observe in the HRS dataset, however, are 2-period ahead probabilities, $\operatorname{Pr}\left(h_{t+2}=j \mid h_{t}=i\right)$. The two sets of probabilities are linked, however, by

$$
\begin{aligned}
\operatorname{Pr}\left(h_{t+2}=j \mid h_{t}=i\right) & ={ }_{k} \operatorname{Pr}\left(h_{t+2}=j \mid h_{t+1}=k\right) \operatorname{Pr}\left(h_{t+1}=k \mid h_{t}=i\right) \\
& ={ }_{k} \pi_{k j, t+1} \pi_{i k, t}
\end{aligned}
$$

This allows us to estimate $\left\{\beta_{k}\right\}$ directly from the data using maximum likelihood.

\section{B.3 Health Insurance Types}

For health insurance type, we will have retiree/tied/private/self-insure/Medicaid/Medicare. We assume Medicaid + Medicare is available to everyone who is disabled. The vast majority of individuals in the 50-64 age range who are drawing Medicaid or Medicare benefits do so because of DI/SSI recipiency. We assume that all disabled people can draw DI benefits, and SSI benefits if they earn below a threshold level and their DI benefit would have been low in the absence of the benefit. Consistent with the facts (describe here), many people lose cash benefits because of work status, but do not lose their health insurance benefits.

\section{B.4 Discrete Hours Choices}

We assume that individuals can choose hours on a discrete grid. To be precise, $N_{t} \in\{500,1000,1500,2000,2500,3000,3500\}$. The main reason is that it is much easier to handle Medicaid/Medicare eligibility cutoffs in terms of earned income this way, compared to the alternative of interpolating between these values as in French and Jones, (2011).

\section{B.5 Spousal Income}

Because spousal income can serve as insurance against medical shocks, and because marital status affects eligibility for Medicaid, we include it in the model. We denote the presence of a spouse with the indicator $S P_{t}$, which equals 1 if the head is married and is 0 if he is single. For married $\rightarrow$ unmarried transitions, we do not distinguish between divorce and spousal death. 
We assume that when a spouse is present, spousal income $y s_{t}$ takes on two values: (i) zero; or (ii) a positive value that varies with age. With this assumption, we can collapse marital status and spousal earnings into a single variable, $\Upsilon_{t} \in\{$ single, spouse with no income, spouse with positive income $\}$. We assume the transition probabilities for $\Upsilon_{t}$ are logistic functions of its current value, the health of the household head, and age. We estimate the probabilities form the HRS, using the same approach to reconcile 1-year and 2-year transition probabilities that we used when estimating the health transition probabilities.

\begin{tabular}{|c|c|c|c|}
\hline \multicolumn{4}{|c|}{ Ages $50 \rightarrow 51$} \\
\hline \multirow{4}{*}{$\begin{array}{r}\text { Current Year } \\
\text { Single }\end{array}$} & \multicolumn{3}{|c|}{ Next Year } \\
\hline & & Spouse & Spouse \\
\hline & Single & without income & with income \\
\hline & 97.2 & 0.8 & 0.2 \\
\hline Spouse without income & 1.7 & 86.9 & 11.4 \\
\hline Spouse with income & 1.6 & 8.7 & 89.7 \\
\hline \multicolumn{4}{|c|}{ Ages $60 \rightarrow 61$} \\
\hline \multirow{4}{*}{$\begin{array}{r}\text { Current Year } \\
\text { Single }\end{array}$} & \multicolumn{3}{|c|}{ Next Year } \\
\hline & & Spouse & Spouse \\
\hline & Single & without income & with income \\
\hline & 96.1 & 1.2 & 2.7 \\
\hline Spouse without income & 1.2 & 83.0 & 15.8 \\
\hline Spouse with income & 1.0 & 6.1 & 92.8 \\
\hline \multicolumn{4}{|c|}{ Ages $70 \rightarrow 71$} \\
\hline \multicolumn{4}{|c|}{ Next Year } \\
\hline \multirow{3}{*}{$\begin{array}{r}\text { Current Year } \\
\text { Single }\end{array}$} & & Spouse & Spouse \\
\hline & Single & without income & with income \\
\hline & 97.5 & 0.5 & 2.0 \\
\hline Spouse without income & 2.3 & 66.2 & 31.5 \\
\hline Spouse with income & 1.3 & 2.5 & 96.2 \\
\hline \multicolumn{4}{|c|}{ Ages $80 \rightarrow 81$} \\
\hline \multirow{4}{*}{$\begin{array}{r}\text { Current Year } \\
\text { Single }\end{array}$} & \multicolumn{3}{|c|}{ Next Year } \\
\hline & & Spouse & Spouse \\
\hline & Single & without income & with income \\
\hline & 99.0 & 0.2 & 0.9 \\
\hline Spouse without income & 5.4 & 48.4 & 46.2 \\
\hline Spouse with income & 2.6 & 1.2 & 96.1 \\
\hline
\end{tabular}

Table 11: Spousal Transition Probabilities: Household Head in Good Health

Table 11 shows transition probabilities for selected years when the household head is in good health. (The patterns are similar for all health states.) As households age, they are more 
likely to become single. In addition, as households age spouses without income are more likely to transition to having income. This likely reflects the initiation of Social Security or SSI benefits.

Next, we estimate mean spousal income, conditional on positive income, as a function of health status and age. 